\title{
Zemin ve Deprem Parametrelerinden İvme Azalım İlişkisi
}

\section{Attenuation Relationship for Peak Horizontal Acceleration from Ground and Earthquake Parameters}

\author{
Osman Uyanık ${ }^{1 *}$, Nevbahar Ekin ${ }^{2} \oplus$, Onur Çoşkun ${ }^{3}$ \\ 1,2 Süleyman Demirel Üniversitesi, Mühendislik Fakültesi, Jeofizik Mühendisliği Bölümü, Isparta \\ ${ }^{3}$ Süleyman Demirel Üniversitesi, Fen Bilimleri Enstitüsü, Jeofizik Mühendisliği Anabilim Dalı, Isparta \\ Sorumlu Yazar / Corresponding Author *:osmanuyanik@sdu.edu.tr
Geliş Tarihi / Received: 14.08.2020 Araștırma Makalesi/Research Article Kabul Tarihi / Accepted: 15.10.2020 DOI:10.21205/deufmd.2021236820
Atıfsekli/How to cite: UYANIK O., EKIN N., COSKUN O. (2021). Zemin ve Deprem Parametrelerinden İvme Azalım İlişkisi. DEÜFMD 23(68), 575-593. \\ Öz
}

Bu çalıșmada, mühendislik yapıları için önemli bir parametre olan ve depremde meydana gelen pik yatay yer ivme değeri tahmin edilmiştir. Yatay yer ivme değeri konusunda çalışan araştırmacıların çoğunluğu sadece deprem parametrelerini, çok azı ise zemin parametrelerinden bazılarını deneysel ilișkilerinde kullanmışlardır. Bilindiği üzere pik yatay yer ivme değeri yerin özelliklerine bağlı değişkenlik göstermektedir. Bu nedenle yapılan çalışmada hem zeminin dinamik parametrelerini hem de deprem parametrelerini kullanarak çok parametreli yeni bir ivme azalım ilișkisi elde edilmiștir. Bu ilișkide deprem parametreleri olarak depremin büyüklügü, periyodu ve kaynak mesafesi ve zeminin dinamik parametreleri olarak da zeminin büyütmesi, hakim titreșim periyodu, $30 \mathrm{~m}$ derinlik için $\mathrm{P}$ ve $\mathrm{S}$ dalga hızlarının ağırlıklı ortalamaları (Vp30 ve Vs30) kullanılmıștır. Bu kapsamda, dünyadaki farklı istasyonlardan elde edilen $\mathrm{M}_{\mathrm{w}}=5.3-7.1$ aralığındaki büyüklüklerde 152 adet deprem kaydının sonuçları ve istasyon yerinin dinamik parametrelerinden elde edilen verilerle veri seti oluşturulmuştur. Çalışma kapsamında geliştirilen deneysel azalım ilişkisi, literatürdeki diğer araştırmacıların deneysel ilişkileri ile karşılaştırılmış ve daha düşük RMSE hata elde edilmiştir.

Anahtar Kelimeler: Yatay yer ivmesi, Depremin büyüklügüü,Uzaklık, Zemin büyütmesi, Sismik P ve S dalga hızları

\begin{abstract}
In this study, the value of the peak horizontal ground acceleration occurred in the earthquake and which is an important parameter for the engineering structures was estimated. Most of the researchers working on the peak horizontal ground acceleration value subject used only earthquake parameters and few used ground parameters in their empirical relationships. As known, the value of the peak horizontal ground acceleration varies depending on the properties of the ground. Therefore, a new multi-parameters attenuation relationship for peak horizontal acceleration was obtained by using both the dynamic parameters of the soil and the earthquake parameters. In this relationship, magnitude, period and source distance of the earthquake are used as earthquake parameters, and soil magnification, soil predominant period, weighted averages of $\mathrm{P}$ and $\mathrm{S}$ wave velocities for $30 \mathrm{~m}$ depth $\left(\mathrm{Vp}_{30}\right.$ and $\left.\mathrm{Vs}_{30}\right)$ are used as dynamic parameters of the ground. In this context, the data obtained from dynamic parameters of station ground and from results of 152 earthquake records of Mw=5.3-7.1 magnitudes obtained from different stations in the world were formed as data set. The empirical attenuation relationship developed within the scope of the study was compared with that of other researchers in the literature and a lower RMSE error was obtained.
\end{abstract}

Keywords: Horizontal ground acceleration,Magnitude,Distance, Soil amplification, Seismic P and $S$ wave velocities 


\section{Giriş}

Önemli bir deprem kuşağında yer alan Türkiye'de, bir bölgede yer alan veya yerleşime açılacak yeni makro veya mikro ölçekli mühendislik projelendirmelerinde, özellikle deprem hasarlarının en aza indirgenmesi ve gerekli önlemlerin alınması açısından yapılara etki edecek deprem kuvvetinin doğru hesaplanması oldukça önemlidir. Bu önemine karşılık, Ülkemizde, birçok inşaat hesaplamalarında ivme değeri, "Türkiye Bina Deprem Yönetmeliği"nde belirtilen tablolardan sabit alınmaktadır. Bilingiği gibi, ivme değeri sabit bir değer olmayıp yerin özelliklerine bağlı olarak değişkenlik göstermektedir. Bu yüzden, literatürde 1950'li yıllardan beri birçok ivme azalım ilişkisi geliștirildiği literatürden bilinmektedir. Deprem dalgalarının yapıya uyguladığı yanal kuvvet olarak tanımlanan yatay deprem ivmesinin hesaplanması amaciyla dünyanın birçok noktasına kurulan deprem istasyonlarındaki deprem kayıtları kullanılmaktadır. $\mathrm{Bu}$ kayıtlar ivmeölçerler tarafından kaydedilmektedir. Ölçülen deprem kayıtları yırtılan fayın yüzeyinden kayıt cihazına aktarılan sismik enerjinin çok karmaşık işlemlerinin toplamını sunmaktadır.

Dünyanın her noktasından veri elde etmek mümkün olmadığı için birçok araştırmacı tarafından geliştirilen ampirik bağıntılar yardımı ile yatay ivme değerleri hesaplanabilmektedir. Ancak bu araștırmacıların bağıntılarında genellikle kaya etkisinin göz önünde bulundurulduğu ve deprem parametreleri kullanılarak zemin parametrelerinin ise göz ardı edildiği gözlenmiştir. Bunun en büyük sebeplerinden biri ivmeölçer cihazlarının kaya üzerine kurulmuş olmasından kaynaklanmaktadır. Buna karşın, hem zemin hem de kaya birimlerde ivmeölçer cihazları olan araștırmacılar kaya etkisinin yanı sıra zemin etkisini içeren bazı parametreleri de ivme azalım ilişsilerinde kullanmışlardır. [1], olușturduğu ivme azalım ilişkisinde depremin büyüklüğü, periyodu ve uzaklığına ek olarak zemin hakim titreşim periyodunu da kullanmıştır. Literatürdeki diğer ampirik bağıntılarda ise genellikle uzaklık (R) parametresi ile birlikte lokal büyüklük $\left(\mathrm{M}_{\mathrm{L}}\right)$ [2-8], yüzey dalgası büyüklük (Ms) [9-16] veya moment büyüklük $\left(\mathrm{M}_{\mathrm{w}}\right)$ parametrelerini [17-23] kullanılarak ivme azalım ilişkileri geliștirilmiştir. Diğer bazı araștırmacılar ise bu deprem parametrelerine zemin türüne [24-25] veya S dalga hızına (Vs) bağlı olarak değișen bir zemin katsayısı [26-29] ilave ederek ya da Vs30 (30m derinlik için S dalga hızının ağırlıklı ortalaması) veya buna bağlı bir katsayı kullanarak [30-36] ivme azalım ilişkileri geliştirmişlerdir.

Bilindiği gibi yerel zemin özellikleri yer ivmesini önemli derecede etkilemektedir. Örneğin, yumuşak zemin, çok katlı yapıların rezonansına yol açmakta ve yer yüzeyi salınım periyodunu arttırabilmektedir [37]. Dolayısıyla depreme karşı dayanıklı bir yapının tasarlanması için zemin hâkim titreșim periyodu ve zemin büyütmesi gibi dinamik davranıș özelliklerinin nasıl değiștiği önceden belirlenmelidir [38]. Son yıllardaki depremler sonucunda meydana gelen hasarlar ve bu konuda yapılan çalışmalardan elde edilen sonuçlar, zemin özelliklerinin ve zemin tabakalarındaki oturmaların deprem üzerindeki etkisinin çok önemli olduğunu ortaya koymuștur [39-40]. Bu somut göstergeler ve bilgiler ışığında yapılan çalışmada yeni bir Zemin Etkisi (ZE) bağıntısı geliştirilmiştir. Bu bağıntıda zemin büyütmesi (b), zemin hakim titreșim periyodu $\left(\mathrm{T}_{\mathrm{o}}\right), \mathrm{V}_{\mathrm{S} 30},(30 \mathrm{~m}$ 'lik $\mathrm{S}$ dalga hızlarının ağırlıklı ortalaması) ve $\mathrm{V}_{\mathrm{P} 30}$ (30 m'lik $\mathrm{P}$ dalga hızlarının ağırlıklı ortalaması) gibi zeminin dinamik özelliklerini yansıtan parametreler kullanılmıştır. Buna göre, deprem özelliklerini gösteren parametreler olan depremin büyüklüğü $(M)$, uzaklığı $(R)$ ve periyodu $\left(T_{D}\right)$ 'nun yanı sıra zemin etkisini de içerecek şekilde yeni bir ivme azalım ilişkisi geliştirilmiştir. Böylece, hem kaya hem de yumuşak zemin göz önünde bulundurularak geliştirilen bu bağıntı, literatürdeki diğer araștırmacıların bağıntıları ile karşılaştırılmıştır. Ayrıca bu bağıntı ve diğer araștırmacıların bağıntılarından hesaplanan ivme değerleri ile ölçülen ivme değerleri karşılaştırılmış ve ölçülen ile hesaplanan ivme değerleri arasında en düşük hata, geliştirdiğimiz ve önerilen bağıntıdan elde edilmiştir.

\section{Deprem ve Zemin Parametrelerinin İvme- Azalım İlişkilerine Etkisi}

Zemine ait dinamik ya da statik parametrelerin (Zemin sıvılaşması, zemin büyütmesi, zemin hakim titreşim periyodu ve yapı periyodu, zeminin ivme değeri, alüvyon kalınlığının etkisi, zeminin taşıma gücü, zeminin $V_{s_{30}}$ değeri, zeminin türü ve bunun gibi) deprem hasarına etkilerinin belirlenmesi gerekmektedir [41-42]. İvme değeri düşük ancak yüksek periyodlu bir deprem, süreye de bağlı olarak büyük hasarlara 
neden olabilmektedir. Ayrıca zemin tabakalarının yapısı, mühendislik yapılarının deprem davranışını etkiler. Deprem dalgaları, depremin oluştuğu derinlikten yer yüzeyinde bulunan yapının temeline doğru zeminin büyütme etkisiyle iletilmektedir. Bu durum, az ya da çok büyütme etkisiyle depremin hissedilmesine neden olabilmektedir. Zemin büyütmesi, yeryüzüne yakın yumuşak zeminlerin içinden geçen sismik dalgaların genliklerini büyütmektedir. Bu durum, yüzeye yakın bu tür zeminlerin yoğunluk $(\rho)$ ve Vs değerlerinden belirlenen empedansının $(\mathrm{Z}=\rho \mathrm{Vs})$ düşük olmasından kaynaklanmaktadır [43]. Buna karşın sismik dalgalar yumuşak zemin tabakaları içinde genliklerin büyütülmesine ek olarak aynı zamanda sönümlenebilir dolayısıyla da genlikleri azalabilmektedir [44]. Deprem ivmesi gibi özellikler bu durumdan etkilenmektedir. Deprem büyüklüğünün, faya dik uzaklığın ve zemin türünün aynı olması durumunda ters faylanmanın oluşturduğu kuvvetli yer hareketinin genliği diğer fay türlerine oranla özellikle faya yakın mesafelerde daha büyük olmaktadır [45].

Özellikle anakaya üzerinde yumuşak ve suya doygun birimler olması durumunda, bu tip alanlarda gerekli önlemler alınmazsa depreme gerek kalmaksızın yapılar eğim doğrultusunda kayabilmektedir. Yeraltı su seviyesinin 10-15 m'den derin olduğu yerlerin deprem hasarı üzerinde pek bir etkisi yok iken; 4-10 m arasında olduğu yerlerde deprem şiddetini 0.5 birim ve 0 $4 \mathrm{~m}$ arasında ise 1 birim arttırmaktadır [46]. Alüvyon ve dolgu ortamların kalınlıkları arttıkça maksimum yer ivmesi ve zemin hakim titreșim periyodu artmaktadır [42]. Zemin hakim titreşim periyodu, bir deprem sırasında zeminin hangi periyotlarla salınacağı konusunda bilgi vermesi açısından önemlidir. Deprem periyodu ve zemin hakim titreşim periyodunun ayn olduğu rezonans durumunda, yatay yer ivmesi değeri en yüksek değerini almaktadır [1]. Bu nedenle, ivme azalım ilişkisinde bu parametrelerin de göz ününde bulundurulması gerekmektedir.

Sismik $\mathrm{P}$ ve $\mathrm{S}$ dalga hızları doğrudan ortamın fiziksel, mukavemet ve elastik özelliklerine bağlı olduğundan, zemin hakkında önemli bilgiler vermekte dolayısıyla da zeminlerin dinamik özelliklerinin belirlenmesinde oldukça yararlı olmaktadır [47-48]. Yine zemin davranışıyla ilgili özellikler (makaslama modülü, sıvılașma potansiyeli vb.) sismik S dalga hızından elde edilmektedir [49]. Ayrıca sismik P ve S dalga hızlarının oranı (Vp/Vs), zeminin gözeneklerinin su $(\mathrm{Vp} / \mathrm{Vs}>3.5)$ ya da hava (Vp/Vs yaklaşı 1.5 civarı) doygunluğu hakkında bilgi vermektedir [50-52]. Ek olarak suya doygun gevşek kum zeminlerde meydana gelebilecek sıvılaşma durumu da sismik hizlardan analiz edilebilmektedir [53-58]. Sonuç olarak zemininin fiziksel ve mekaniksel özelliklerinden sismik hızlar etkilenmekte ve bu nedenle de, ivme azalım ilișkilerinde deprem parametrelerinin yanı sıra zemin etkilerini yansıtan sismik hızların da kullanılmasının daha doğru sonuçlar ortaya koyacağ düșünülmektedir.

\section{Değerlendirmeler}

Çalışma kapsamında, yeni bir ivme azalım ilişkisi ortaya koymak amacıyla dünyadaki farklı istasyonlardan elde edilen $\mathrm{M}_{\mathrm{w}}=5.3-7.1$ aralığındaki büyüklüklerde 152 adet deprem kaydının sonuçları kullanılmıştır. Bu veriler [59] tarafından AFAD (Afet ve Acil Durum Yönetimi Başkanlığı), CESMD (Center for Engineering Strong Motion Data) ve ORFEUS (Observatroies \& Research Facilities for European Seismology) merkezlerinden oluşturulmuş ve bu çalışmada düzenlenerek Ek-1 de sunulmuştur. Burada web sitelerinden elde edilen farklı magnitüdler [60] tarafından geliştirilen magnitüd dönüşüm ilişkilerinden yararlanılarak moment magnitüdüne dönüștürülmüştür. Ayrıca depremin uzaklığı olarak hiposantır uzaklığı (Rhypo) kullanılmıștır. Bağıntının geliştirilmesi amaciyla deprem parametreleri olan depremin büyüklüğü, uzaklığı ve periyodunun yanı sıra zemin büyütmesi, zemin hakim titreşim periyodu, Vs30 ve $\mathrm{Vp}_{30}$ gibi zeminin dinamik özelliklerini yansıtan parametreler de kullanılmıştır (Ek-1). Böylece, zemin etkisine bağlı bir ivme azalım ilișkisi geliştirilmiştir. Gerçek deprem kayıtlarının analizlerinin yanında kuvvetli yer hareketi istasyonunun yer sınıfının belirlenmesi amacıyla Yüzey dalgalarının çok kanallı analizi [61] (MASW) yöntemi uygulanmıș ve derine doğru $S$ dalga hızları AFAD, CESMD ve ORFEUS merkezleri tarafından belirlenmiștir $\{[1-3]\}$. Vs $\mathbf{s}_{30}$ değeri olmayan çok az deprem istasyonlarında bu değer USGS (United States Geological Survey) merkezindeki $\mathrm{Vs}_{30}$ haritalarından belirlenmiștir $\{[4]\}$. Bu hız değerleri belirlenirken kaydedilen MASW verisine ilk olarak faz hızı-frekans 
dönüșümü uygulanmaktadır. Bu ișlem sonucu dalganın dispersiyon eğrisi hesaplanarak görüntülenmektedir. Ölçülen veri ile yeraltının kuramsal modelinin dispersiyon eğrileri birbiri ile çakışana kadar ters çözüm işlemleri yapılmaktadır. Ters çözümden sonra yeraltının derinliklerine göre değișen bir boyutlu S dalga hız modeli elde edilmektedir (Şekil 1).

MASW çalıșmasından derine doğru elde edilen S dalga hızları kullanılarak $\mathrm{T}_{0}$ aşağıdaki şekilde hesaplanabilir.

$T_{0}=\frac{4 h_{1}}{V_{S 1}}+\frac{4 h_{2}}{V_{S 2}}+\frac{4\left(H-\left(h_{1}+h_{2}\right)\right)}{V_{S 3}}$

$T_{0}=\frac{4 H}{V s_{30}} \quad H=30 m$

Eşitlik 1a' da, H derinliği S dalga hızına bağlı 30 ya da $50 \mathrm{~m}$ seçilmektedir. Bu seçim ilk $30 \mathrm{~m}$ içerisinde $\mathrm{Vs}>500 \mathrm{~m} / \mathrm{s}$ elde edilir ise $\mathrm{H}=30 \mathrm{~m}$, $\mathrm{Vs}<500 \mathrm{~m} / \mathrm{s}$ olması durumunda $\mathrm{H}=50 \mathrm{~m}$ kullanılmalıdır [42,62]. Vs30 aşağıdaki şekilde hesaplanmaktadır [42].

$\mathrm{V}_{\mathrm{S} 30}=\frac{30}{\mathrm{t}_{\mathrm{d}}+\frac{30-\mathrm{d}}{\mathrm{V}_{\mathrm{Sson}}}}$

Burada Vsson: d derinliği ile $30 \mathrm{~m}$ arasındaki tabakanın hızıdır, $t_{d}$ : $d$ derinliğine kadar olan tabakalarda dalganın yayılma zamanıdır. Ayrıca zeminin yoğunluğu, $P$ ve $S$ dalga hızlarının birlikte kullanılması ile hesaplanabilmektedir [63-64].

$\rho=0.7\left(V_{p} V_{s}\right)^{0.08}$

Yapılan çalışmada P ve S dalga hızlarının, yerine $\mathrm{Vp}_{30}$ ve $\mathrm{Vs}_{30}$ kullanılarak $30 \mathrm{~m}$ derinlik için yoğunluk $\left(\rho_{30}\right)$ değeri belirlenmiștir. Ayrıca $30 \mathrm{~m}$ derinlik için zemin büyütmesi (b) değerleri aşağıdaki eşitlik kullanılarak hesaplanmıştır [65].

$\mathrm{b}=\left(\frac{V_{P 30}}{V_{S 30}} \frac{3.5}{\rho_{30}}\right)^{0.1}\left(\frac{750}{V_{S 30}}\right)^{0.5}$

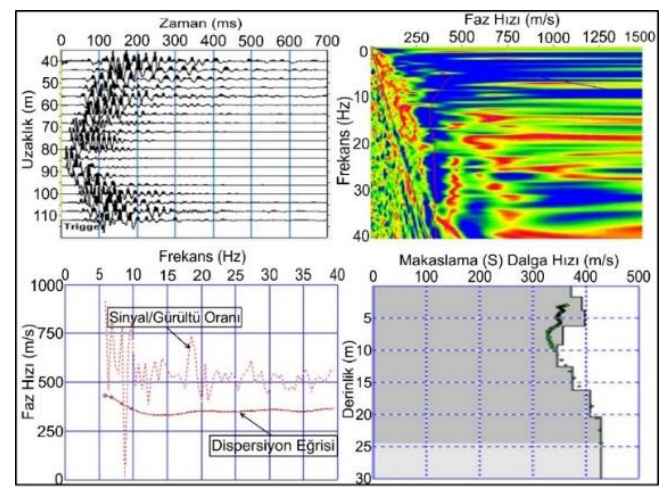

Şekil 1. Çok kanallı yüzey dalgalarının analizi (MASW)

\subsection{Deprem ve zemin etkisine bağlı ivme- azalım ilişkisinin geliştirilmesi}

Yatay yer ivmesinin, depremin periyoduna, uzaklığına ve büyüklüğüne bağlı olarak etkin bir biçimde değiștiği bilinmektedir. Bu çalıșmadaki veriler kullanılarak yatay yer ivmesinin moment büyüklüğüne bağlı olarak deprem periyodu ile değişimi Şekil 2'de gösterilmiştir. Buradaki deprem periyodu değerlerini belirlemek için [66]'de verilen abağı [54] matematiksel olarak ifade etmiștir [59].

$\mathrm{R} \leq 40 \mathrm{~km}$ için; $\quad T_{D}=0.0681 \mathrm{M}_{w}-0.17$

$\mathrm{R}>40 \mathrm{~km}$ için; $T_{D}=\left(0.0008 \mathrm{M}_{w}-0.0031\right) R+$ $0.0322 \mathrm{M}_{w}-0.0175$

Buna göre depremin büyüklüğü arttıkça deprem periyodu da artmakta yatay yer ivmesi ise buna bağlı olarak üstel olarak azalmaktadır. Kullanılan veri sayılarının kısıtlı olmasından dolayı eğrilerin sınırları değișmektedir. Özellikle 6.3 ve 7.0 moment büyüklüğüne ait veri sayısının fazla olmasından kaynaklı veri sınırları diğerlerine göre farklıdır. Ancak Şekil 2'den anlaşılacağı üzere, moment büyüklüğü sabitlendiğinde yatay yer ivmesi ile deprem periyodu arasında üstel bir ilişki olduğu görülmektedir. Ek olarak Şekil 2'de uzaklık dikkate alınmamaktadır. Ancak bilinmelidir ki uzaklık arttıkça deprem dalgasının periyodu büyür buna karşın ivme değeri azalmaktadır. 


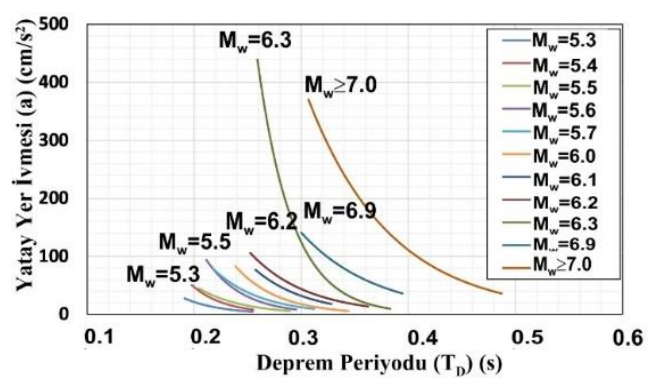

Șekil 2. Moment büyüklüğüne bağlı sınıflandırılan verilerin deprem periyodu ile yatay yer ivmesi arasındaki ilişkileri

Zemin hakim titreşim periyodu ile yatay yer ivmesi arasında çalışılan verilerin sunduğu eğilim Şekil 3'de görülmektedir. Şekil 3A ve 3B' de, sırasıyla moment büyüklükleri 5.3-6.3 ve 6.7-
7.1 olarak seçilmiș ve uzaklığa bağlı (10-50 ve $50-100 \mathrm{~km}$ ) olarak sınıflandırılmıştır. Buna göre zeminin hakim titreşim periyodu arttıkça, ivme değeri genel itibariyle artıș göstermektedir. Depremin büyüklüğü 5.3-6.3 arasında iken $50 \mathrm{~km}$ uzaklığa kadar zemin hakim titreşim periyodu arttıkça çok az ivme artışı görülürken, $50 \mathrm{~km}$ den daha büyük uzaklıklarda bu artış görülmemektedir. Buna karşıllk Şekil 3B'de depremin büyüklüğünün 6.7-7.1 arasında olması durumunda ve $50 \mathrm{~km}$ den daha az olan uzaklıklarda zemin hakim titreșim periyodunun artışı ile ivme değerinin çok arttığı ve $50 \mathrm{~km}$ den daha fazla olan uzaklıklarda elde edilen verilerde bu artıșın sürdüğü fakat daha az olduğu görülmektedir.

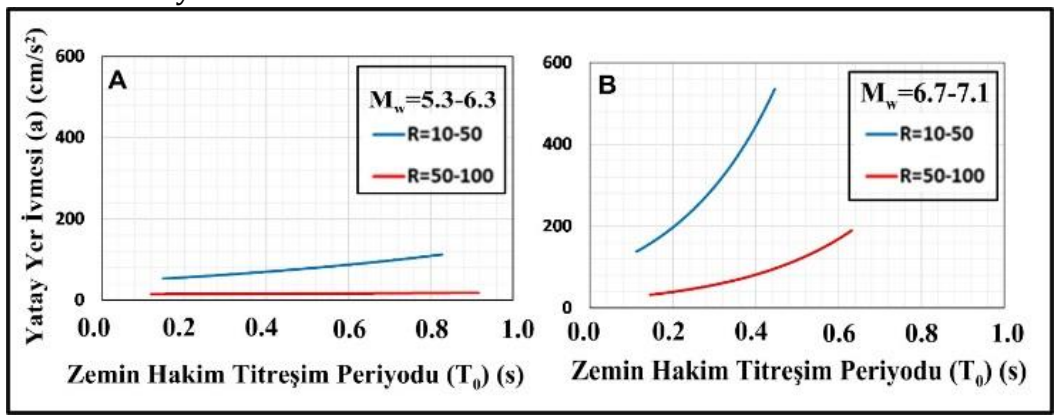

Şekil 3. Depremin büyüklüğü ve uzaklığına bağlı sınıflandırılmış verilerin yatay yer ivmesi ile zemin hakim titreşim periyodu $\left(\mathrm{T}_{0}\right)$ arasındaki ilişkiler

Sekil 3'e benzer olarak deprem dalgasının periyodu ile zemin hakim titreşim periyodunun oranı $\left(\mathrm{T}_{\mathrm{D}} / \mathrm{T}_{0}\right)$ ve yatay yer ivmesi arasında Moment büyüklüğü ve uzaklığa bağlı sınıflandırılmıș verilerin ilișkileri Șekil 4'de sunulmuştur. Buna göre $\mathrm{T}_{\mathrm{D}} / \mathrm{T}_{0}$ oranı arttıkça, ivme değerleri genel itibariyle logaritmik olarak azalmaktadır. Bu durum, Şekil 4B'de moment büyüklüğünün yüksek olduğu ve $50 \mathrm{~km}$ den daha az uzaklıklarda olan depremlerden elde edilen verilerde net olarak görülmektedir.

Şekil 5'te yatay yer ivmesi ile zemin büyütmesi arasında depremin büyüklüğü ve uzaklığına bağlı sınıflandırılmış verilerin ilişkileri gösterilmiștir. Șekil 5 genel olarak incelendiğinde, zemin büyütme değerinin artıșı ile yer ivmesinin arttığı görülmektedir. Bu artış oranı depremin moment büyüklügünün yüksek ve uzaklığın yakın olduğu yerlerde net olarak görülmektedir.
Şekil 6'da ise diğer șekillere benzer olarak yatay yer ivmesi ve zeminin Vs 30 değeri ile değișimi sunulmuştur. Bilindiği üzere $V_{s_{30}}$ zeminin sıkılığını ya da katılığını yansıtan bir parametredir. Dolayısıyla, Vs 30 değeri arttıkça ivme değerinin azalması beklenilen bir sonuçtur. $\mathrm{Bu}$ durum deprem büyüklügünün yüksek ve uzaklığın yakın olduğu depremlerde daha net görülmektedir.

Şekil 7'de ise yatay yer ivmesi ile ivmeölçer cihazların kurulduğu ortamın $30 \mathrm{~m}$ derinliğine kadar olan yoğunlukların ortalama değerleri arasındaki ilişkiler gösterilmiştir. Şekil incelendiğinde, zeminin yoğunluğu genel itibariyle $1.6-2.5 \quad \mathrm{gr} / \mathrm{cm}^{3} \quad$ aralığında değişmektedir. Genel olarak ortamın yoğunluğu arttıkça yatay yer ivme değeri azalmaktadır. Bu durum depremin büyüklüğünün yüksek ve uzaklığının yakın olduğu yerlerde daha net olarak görülmektedir. 


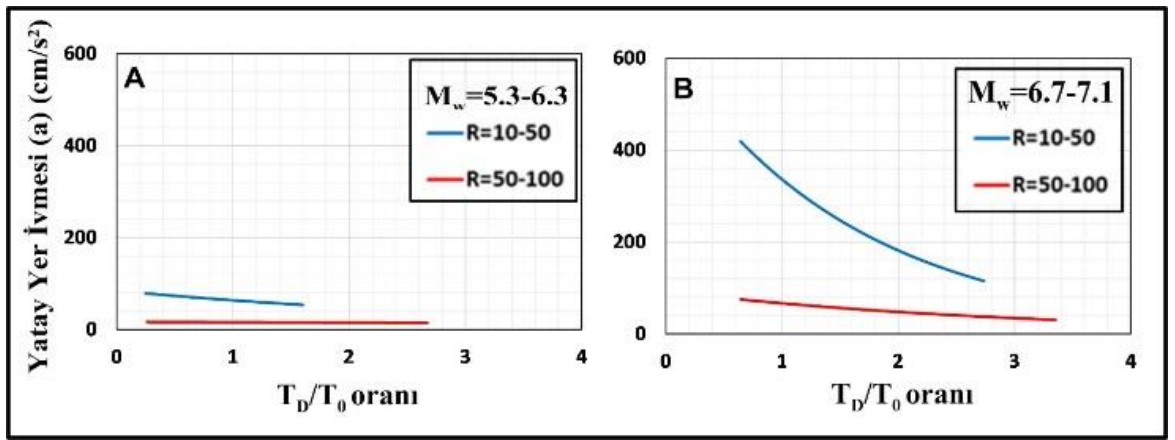

Şekil 4. Depremin büyüklüğü ve uzaklığına bağlı sınıflandırılmış verilerin yatay yer ivmesi ile $\mathrm{T}_{\mathrm{D}} / \mathrm{T}_{0}$ oranı arasındaki ilişkiler

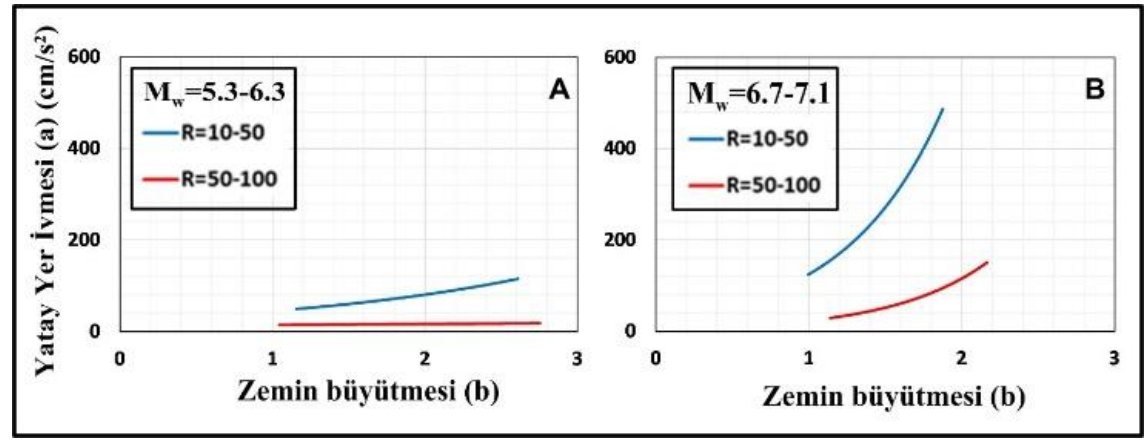

Şekil 5. Depremin büyüklüğü ve uzaklığına bağlı sınıflandırılmış verilerin yatay yer ivmesi ile zemin büyütmesi arasındaki ilișkiler

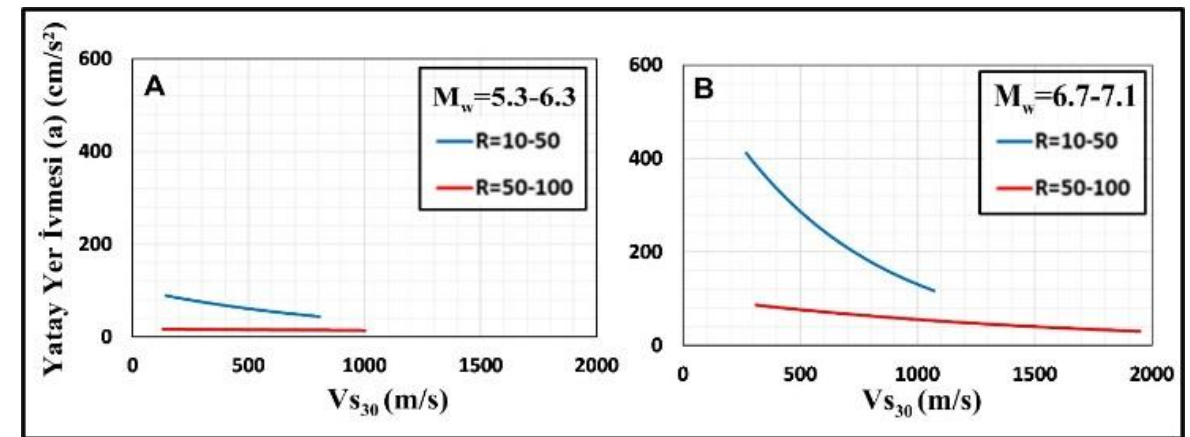

Şekil 6. Depremin büyüklüğüne ve uzaklığına bağlı sınıflandırılmış verilerin yatay yer ivmesi ile Vs30 arasındaki ilișki 
DEÜ FMD 23(68), 575-593, 2021

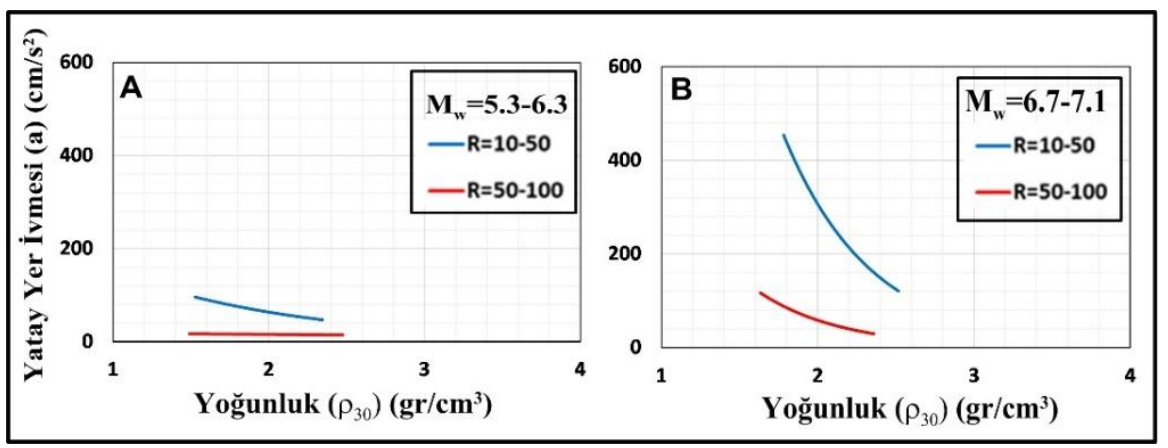

Şekil 7. Depremin büyüklüğüne ve uzaklığına bağlı sınıflandırılmış verilerin yatay yer ivmesi ile yoğunluk ( $\left.\rho_{30}\right)$ arasındaki ilişki

Literatürde, hesaplanan ivme değerleri ile ölçülen ivme değerleri arasındaki hata oranlarının yüksek çımmasındaki nedenlerden birinin deprem büyüklük aralığının geniș olması ve diğer bir nedenin de zemin etkisinin bağıntılarda kullanılmaması olduğu düşünülmektedir. Bu nedenle yapılan çalışmada, deprem parametrelerinin yanı sıra deprem kaydının alındığı yere ait parametrelerin ivme değerine etkisi Şekil 3-7 arasında gösterilmiștir. Zeminden elde edilen bu parametrelerin ivme değeri üzerindeki etkilerinden dolayı zemin etkisi (ZE) parametresi geliştirilmiştir. Zemin etki parametresi; zemin büyütmesi, $\mathrm{Vs}_{30}, \mathrm{Vp}_{30}$, zemin hakim titreşim periyodu, $\mathrm{Vs}_{30} / \mathrm{Vp}_{30}$ oranı,
$\mathrm{T}_{\mathrm{D}} / \mathrm{T}_{0}$ oranını kapsamakta ve aşağıdaki eşitlik ile ifade edilmektedir.

$$
Z E=1+\frac{1}{\sqrt{\left[\frac{1}{b}\left(1+\frac{T_{D}}{T_{0}}\right)^{2}+\left(1-\frac{T_{D}}{T_{0}}\right)^{2} \frac{V_{S 30}}{V_{P 30}}\right]}}
$$

Burada $\mathrm{T}_{\mathrm{D}}$; deprem dalgasının periyodunu ifade etmektedir.

Belirlenen zemin etkisi parametresinin zemin büyütmesi ve Vs30 ile değişimi Şekil 8'de verilmiştir. Buna göre, zemin büyütmesinin artışı ile ZE logaritmik olarak artarken, Vs 30 artışı ile ZE logaritmik olarak azalmaktadır.

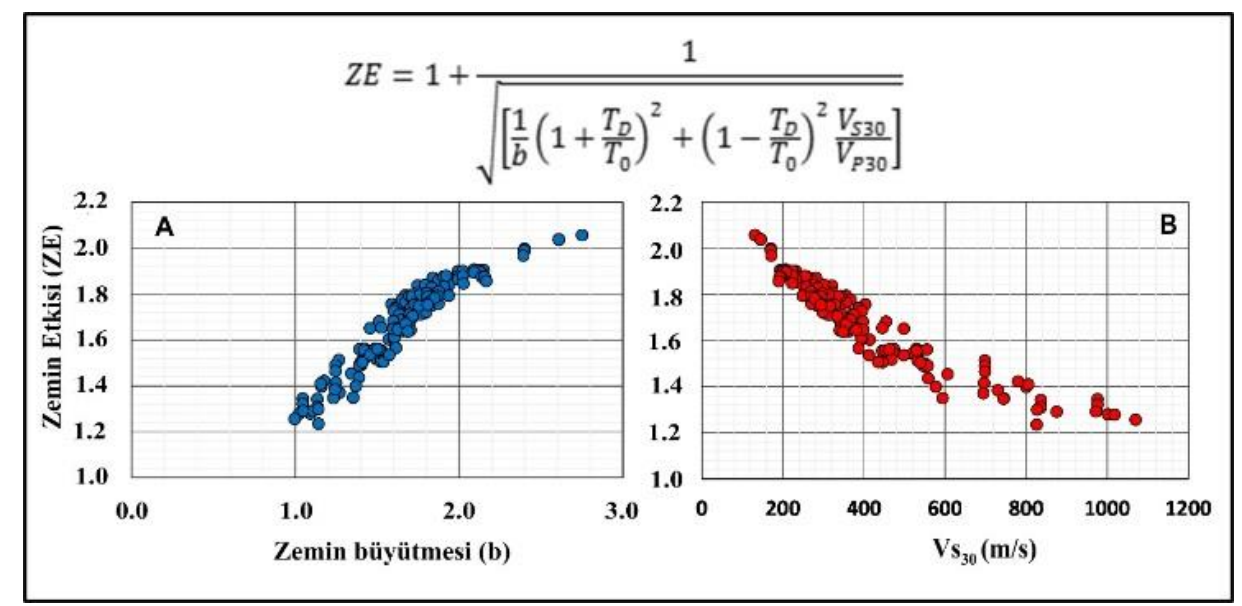

Şekil 8. Zemin Etkisi (ZE) ile A) Zemin Büyütmesi (b) ve B) Vs30 arasındaki ilişki

Yapılan çalıșmada, ZE parametresi özellikleri bir arada değerlendirilerek SPSS-20 tanımlandıktan sonra, deprem ve zemin istatistik veri analiz programı [67] ile zemin 
etkisine bağlı yeni bir ivme azalım bağıntısı geliştirilmiştir. $\mathrm{Bu}$ ilişkide kullanılan deprem büyüklüklerinin hepsi [60] tarafindan geliştirilen magnitüd dönüşüm ilişkileri ile moment büyüklüğüne dönüştürülerek kullanılmıștır.

$a=\left[10^{\left(\mathrm{A}_{1} \mathrm{M}_{\mathrm{W}}+\mathrm{A}_{2} \log \mathrm{R}_{\mathrm{Hypo}}+\mathrm{A}_{3} \frac{\mathrm{V}_{\mathrm{P} 30}}{\mathrm{~V}_{\mathrm{S} 30}}\right)}\right][\mathrm{ZE}]$
Bağıntıdaki, $\quad \mathrm{M}_{\mathrm{w}}$ : depremin moment

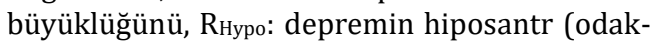
istasyon) uzaklığını göstermektedir. Azalım bağıntısı geliştirilirken belirlenen katsayılara ait en iyi sonuçlar \% 95 güven aralığında alt ve üst sınır değerleri ve standart sapma miktarları ile birlikte Tablo 1'de verilmiștir. Yatay yer ivmesinin sabit uzaklık, Vs30 ve Vp30 değerleri için Moment büyüklük ile arasındaki ilișki yumuşak zemin $(\mathrm{ZE}=2.04)$ ve kaya ortam (ZE=1.08) için ayrı ayrı Șekil 9'da gösterilmiştir.

Tablo 1. SPSS paket programında regresyon analizi sonucu bu çalışmada belirlenen Eşitlik 8'e ait katsayı değerleri

\begin{tabular}{|l|l|l|l|l|}
\hline \multirow{2}{*}{ Parametre Tahmini } \\
\hline \multirow{2}{*}{ Parametre } & \multirow{2}{*}{$\begin{array}{l}\text { Belirlenen } \\
\text { Katsayı }\end{array}$} & $\begin{array}{l}\text { Standart } \\
\text { Sapma }\end{array}$ & Alt Sınır & Üst Sınır \\
\cline { 5 - 6 } & 0.621 & 0.023 & 0.575 & 0.632 \\
\hline $\mathbf{A}_{\mathbf{1}}$ & -1.179 & 0.100 & -1.376 & -1.053 \\
\hline $\mathbf{A}_{\mathbf{2}}$ & -0.081 & 0.022 & -0.125 & -0.054 \\
\hline $\mathbf{A}_{\mathbf{3}}$ & & & & \\
\hline
\end{tabular}

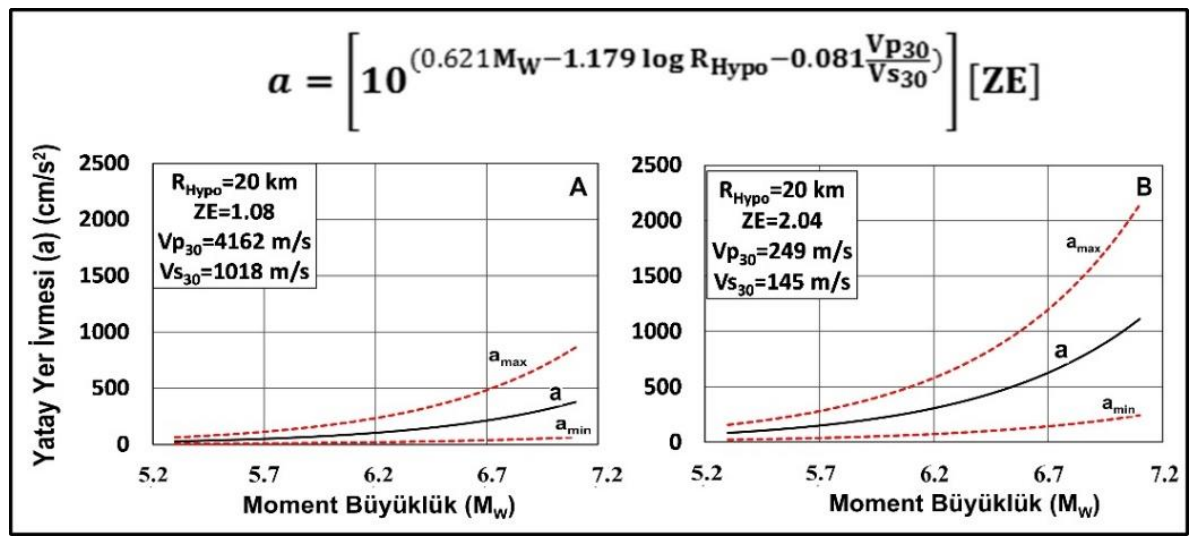

Şekil 9. Moment büyüklük ile Yatay Yer İvmesi arasındaki ilişki A) Kaya ortam için B) Zayıf zemin ortam için

Bu şekiller incelendiğinde, 5.3-7.1 aralığındaki depremlerde depremin büyüklügü arttıkça, kaya ortamda yatay yer ivmesi $10-500 \mathrm{~cm} / \mathrm{s}^{2}$ aralığında, yumuşak zemin için ise 100-1100 $\mathrm{cm} / \mathrm{s}^{2}$ değerine kadar üstel olarak artış göstermektedir. Sonuç olarak depremin büyüklügü arttıkça ivme değerinin de yumuşak zemin ya da kaya ortamlar için arttığı görülmektedir. $\mathrm{Bu}$ artış, yumuşak zeminlerde daha fazladır.

Eşitlik 8 kullanılarak ivme değerinin uzaklığa bağlı değişimini göstermek için Moment büyüklük, $V_{S_{30}}$ ve $V p_{30}$ değerleri sabit alınarak kaya ortam (ZE=1.08) ve yumuşak zemin (ZE=2.04) için Şekil 10 hazırlanmıştır. 


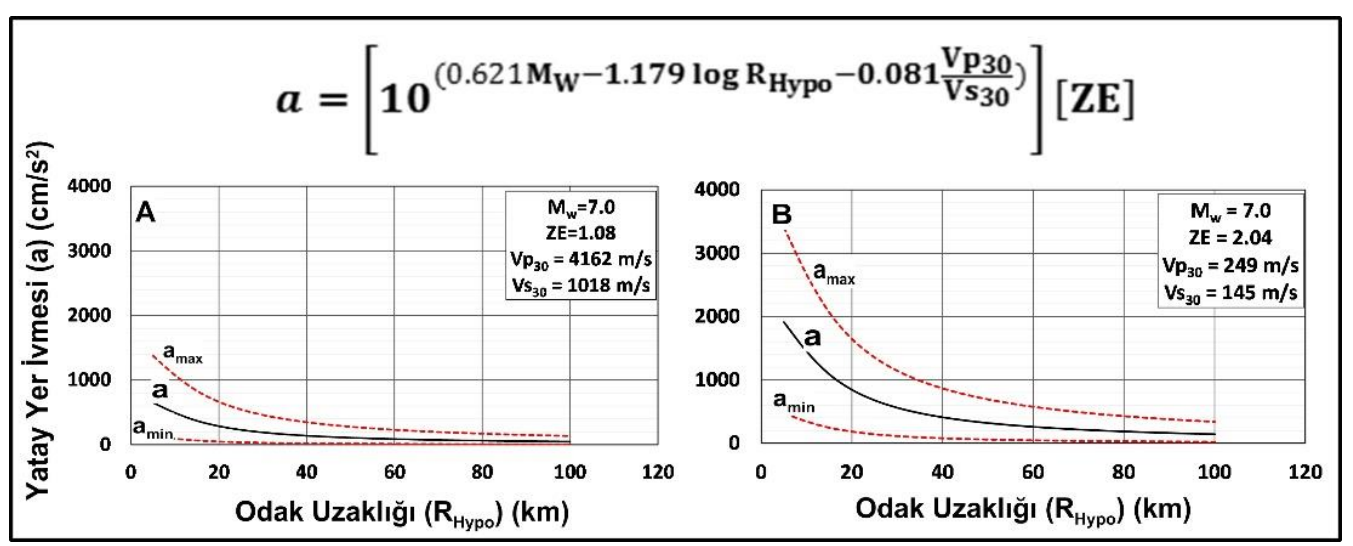

Şekil 10. Odak Uzaklığı ile Yatay Yer İvmesi arasındaki ilişski A) Kaya ortam için B) Zayıf zemin ortam için

Bu şekiller incelendiğinde, $100 \mathrm{~km}$ 'ye kadar olan depremlerde depremin uzaklığı arttıkça, kaya ortamda yer ivmesi yaklaşık $50-800 \mathrm{~cm} / \mathrm{s}^{2}$ aralığında, yumușak zeminde ise $100-1900$ $\mathrm{cm} / \mathrm{s}^{2}$ değerleri arasında üstel olarak azalmaktadır. Yüksek değerler depremin çok yakınında olan yerlerde elde edilirken, depremden uzaklaşıldıkça ivme değerinin azaldığı görülmektedir. Depreme çok yakın olan ortamlar çok kötü zeminlere sahip ise ivme değeri daha da artmaktadır. Dolayısı ile depremin ivmesi zeminin özelliklerine bağlı artış sunmaktadır. $\mathrm{Bu}$ durum göstermektedir ki yapılaşma hesaplarında depremin ivmesinin tablolardan sabit bir değer olarak alınması hem ekonomik kayıplara hem de can kaybına yol açacaktır.

\section{2 İvme-azalım ilişkileri ile karşılaştırma}

Bazı araştırmacılara ait literatürdeki ivmeazalım ilişkileri Tablo 2'de gösterilmiştir. Bu araştırmacılardan [1] dişındakiler hesaplamalarda genellikle sadece büyüklük ve uzaklık parametrelerini kullanmışlardır. [1]'de ise deprem ve hakim titreșim periyodları da kullanılarak bir ivme azalım ilişkisi geliştirilmiştir.

Söz konusu araştırmacıların Tablo 2'de verilen araștırmacılara ait ivme azalım ilişkileri ve bu çalışmada geliștirilen zemin etkisine bağlı ivme azalım bağıntısından hesaplanan ivme değerleri, ölçülen ivme değerleri (ivme değerleri 3.8-806 $\mathrm{cm} / \mathrm{s}^{2}$ aralığında) ile karşılaştırılarak RMSE hata oranlarına bağlı olarak Şekil 11'de gösterilmiștir. Buna göre ölçülen ve hesaplanan ivme değerleri arasındaki farkın, [1-2, 68-69] tarafından verilen bağıntılarda diğer araștırmacıların bağıntılarına göre, daha az olduğu ve bu çalıșmadan elde edilen hatanın ise çok daha az olduğu belirlenmiştir. Belirlenen RMSE değerleri diğer araștırmacılarda 81-198 cm/ $\mathrm{s}^{2}$ aralığında değişirken, çalışmamızda RMSE $78.1 \mathrm{~cm} / \mathrm{s}^{2}$ olarak belirlenmiștir.

Geliştirilen ivme-azalım bağıntısının ve yukarıda verilen literatürdeki bazı ivme azalım ilișkileri arasındaki tutarlılığı ölçmek amacıyla Dünya'da gerçekleşmiş önemli ivme değerlerine sahip, çeşitli ivmeölçer istasyonları tarafından kaydedilmiş depremlerin kuvvetli yer hareketi (ivme) kayıtları ve kayıtçı istasyonları kullanılmıştır. Şekil 12'de 7.0 büyüklüğündeki ve $10 \mathrm{~km}$ derinliğindeki (h) bir deprem için literatürdeki ve bu çalıșmadan elde edilen ilișkiler karşılaștırılmıştır. $\mathrm{Bu}$ çalıșma kapsamında geliștirilen bağıntı kullanılarak hem yumuşak zemin $(\mathrm{ZE}=2.04)$ hem de kaya ortam (ZE=1.08) için ayrı ayrı ivme-azalım ilişki eğrileri gösterilmiștir. Zemin etkisi değerleri bu çalışmadaki veriler kullanılarak en yumuşak zemin ve en sağlam kaya verilerinden elde edilmiş ve diğer ivme azalım ilişkileri ile karşılaştırmak için bu değerlerin kullanılması uygun görülmüştür. Buna göre, genel olarak, kaya ortamlar için literatürde geliştirilen bağıntılardan hesaplanan ivme değerleri genel de daha dar bir aralıkta değişirken zemin etkisini 
DEÜ FMD 23(68), 575-593, 2021

dikkate alan hesaplamalarda ivme değerleri ilk $40 \mathrm{~km}$ olarak dikkate alındığında daha geniş bir aralıkta değișmiş ve daha yüksek araştırmacıların eşitliklerinden farklı ivme ivme değerleri elde edilmiștir. Deprem değerleri hesaplanmaktadır. Bu çalışmadan elde odağından uzaklaştıkça tüm ilişkilerin birbirine edilen eșitliğin eğrisi kaya ortamlar için diğer yaklaştığı görülmektedir. Bu yakın değerler eşitlikler ile uyumlu iken, özellikle ilk $40 \mathrm{~km}$ de genelde $40 \mathrm{~km}$ den sonra daha net yumuşak zeminlerde daha büyük ivme değerleri görülmektedir. Buna karşın depremin uzaklığı elde edilmektedir.

Tablo 2. Literatürdeki bazı araștırmacılara ait ivme-azalım ilişkileri

\begin{tabular}{|l|l|}
\hline Kaynaklar & Bağıntılar \\
\hline$[1]$ & $\boldsymbol{a}=\frac{10^{\left(0.61 M-1.73 \log R_{e p i}+0.13\right)}}{T_{D}}[A]$ \\
& $A=1+\frac{1}{\left[\left[\frac{1+\alpha_{0}}{\left[1-\alpha_{0}\right.}\right]\left\{\left(1-\left(\frac{T_{D}}{T_{0}}\right)\right)^{2}\right\}\right]^{2}+\left\{\frac{0.3}{\sqrt{T_{0}}}\left(\frac{T_{D}}{T_{0}}\right)\right\}^{2}}$ \\
\hline$[70]$ & $\operatorname{a}=1230 e^{0.8 M}(R+25)^{-2}$ \\
\hline$[71]$ & $\boldsymbol{a}=5600 e^{0.8 M}(R+40)^{-2}$ \\
\hline$[2]$ & $\log a=2.91+0.32 M_{L}-1.43 \log R$ \\
\hline$[5]$ & $\ln a=6.74+0.859 M_{L}-1.8 \ln (R+25)$ \\
\hline$[72]$ & $\log \boldsymbol{a}=0.43+0.23(\mathrm{M}-6)-\log \mathrm{R}-0.0027 \mathrm{R}$ \\
\hline$[73]$ & $\log \boldsymbol{a}=0.65 \mathrm{M}_{\mathrm{s}}-0.9 \log R-0.44$ \\
\hline$[74]$ & $\log \boldsymbol{a}=0.329 \mathrm{M}_{\mathrm{w}}-0.00327 R-0.792 \log R+1.177$ \\
\hline$[69]$ & $\log \boldsymbol{a}=0.4+1.2 \mathrm{M}-0.76 \ln \mathrm{R}-0.0094 \mathrm{R}$ \\
\hline$[68]$ & $\log \boldsymbol{a}=0.505+0.538 * M-\log \left(R+0.00810^{0.5 M}\right)-0.002 R$ \\
\hline$[75]$ & $\log \boldsymbol{a}=2.08-1.001 M_{w}{ }^{2}-1.001(R+1)$ \\
\hline
\end{tabular}




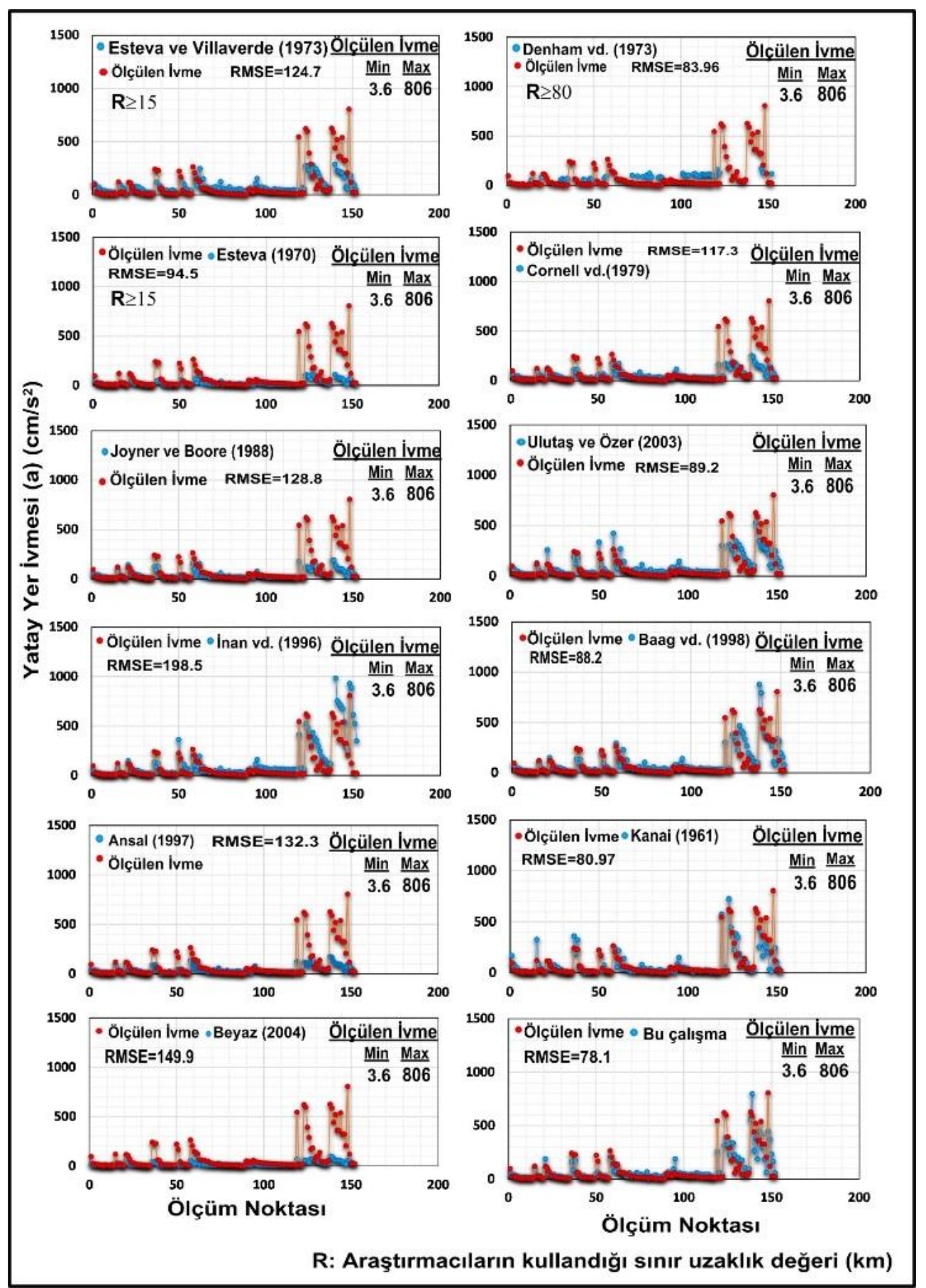

Şekil 11. Ölçülen ve hesaplanan Yatay Yer İvmesi değerlerinin karşılaştırılması 


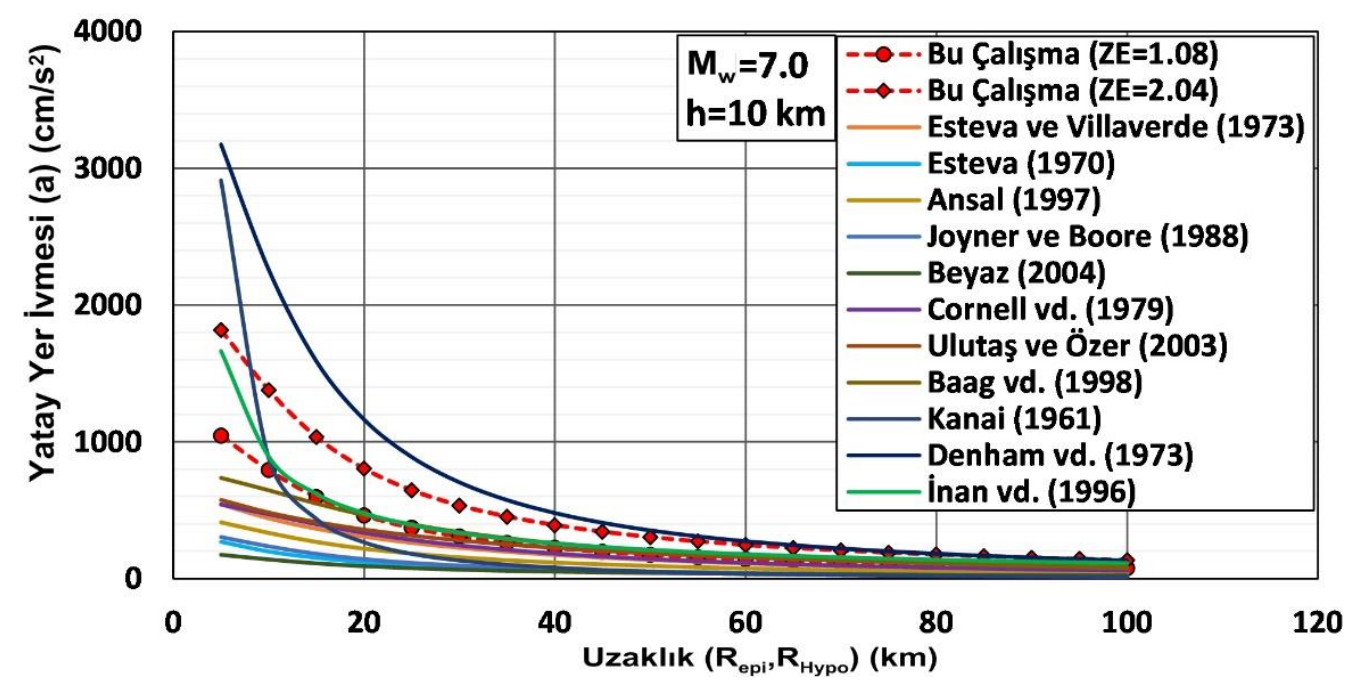

Şekil 12. Literatürden ve bu çalışmadan elde edilen bağıntılara göre hesaplanan yatay yer ivmesinin uzaklığa bağlı değișimi

\section{Sonuçlar}

Dünyanın birçok noktasına kurulmuş olan ivme istasyonlarına ait deprem kayıtları ve bu istasyonların kurulduğu zeminlere ait dinamik parametrelerden yararlanarak bir ivme azalım ilișkisi geliștirilmiștir. Zemin etkisine bağlı olarak geliştirilen bu bağıntı literatürdeki ivme azalım ilişkileri ile karşılaştırılmıştır. Geliştirilen bağıntı hem zemin parametrelerine hem de deprem parametrelerine bağlı olmasından dolayı daha az hata ile ivme sonuçları elde edilmiştir. Ayrıca, literatürdeki ivme bağıntılarının hatalı sonuçlar elde etmesinin diğer bir nedeninin, depremlerin meydana geldiği bölgelerdeki faylanma tipleri ve yerin kabuk yapısının olduğu düşünülmektedir.

$\mathrm{Bu}$ çalıșmanın diğer çalışmalardan elde edilen ivme azalım ilișkilerinden farkı, hem kaya hem de farklı dayanımlara sahip zeminlerdeki kayıtları ve o zeminlere ait zeminin dinamik özelliklerini dikkate almasıdır. Ortaya konulan bağıntıda, zeminin sıkılığını gösteren $S$ dalga hızının $30 \mathrm{~m}$ derinlik için ağırlıklı ortalaması, P dalga hızının $30 \mathrm{~m}$ derinlik için ağırlıklı ortalaması, zemin büyütmesi, deprem dalgasının periyodu ve zemin hakim titreșim periyodu kullanılmıştır. Bu çalışmadan elde edilen eşitlik sınırları 5.3-7.1 moment büyüklük, 0-100 km uzaklık ( $\left.\mathrm{R}_{\text {Hypo }}\right)$ ve $4-800 \mathrm{~cm} / \mathrm{s}^{2}$ ivme değerleri arasındaki verileri kapsamaktadır. Dolayısı ile bu verilerin dışında veriler kullanıldığında eşitliğin katsayılarının değişebileceği dikkate alınmalıdır.

Mühendislik yapılarının hesaplamalarında kullanılan ivme değerlerinin yerin türü ve özelliklerine bağlı değișkenlik göstermesinden dolayı “Türkiye Bina Deprem Yönetmeliği”nde belirtilen tablolardan sabit alınması hatalıdır. $\mathrm{Bu}$ yüzden zemin etkisini de dikkate alan ivme azalım ilişkilerinin kullanılması önerilmektedir.

Çalıșmada geliștirilen bağıntı ve literatürdeki bağıntılar tarafından hesaplanan bazı yüksek ivme değerleri, depremin çok yakınındaki ivme istasyon kayıtlarından elde edilmektedir. $\mathrm{Bu}$ nedenle ivme azalım bağıntıları geliștirilirken, depreme çok yakın istasyon verilerinin kullanımına dikkat edilmesi gerektiği sonucuna varılmıştır.

\section{Teşekkür}

Bu çalışmada kullanılan verilerin birçoğu Afet ve Acil Durum Yönetimi Başkanlığı, Deprem Dairesi'nden (AFAD) sağlanmıștır. Yazarlar; AFAD deprem dairesi yönetimine ve Yük. Jeofizik Müh. Erkan Ateș'e teșekkür ederler. Ayrıca Editör ve hakemlere makalemize koydukları katkılardan ötürü teșekkür ederiz. 


\section{Kaynaklar}

[1] Kanai, K. 1961. An empirical formula for the spectrum of strong earthquake motions, Bulletin of Earthquake Research Institute, Cilt. 39, s. 85-95.

[2] Denham, D., Small, G.R., Everingham, I.B. 1973. Some strong-motion results from Papua New Guinea 1967 1972, In Proceedings of Fifth World Conference on Earthquake Engineering, Cilt. 2, s. 2324-2327.

[3] Ambraseys, N. 1975. Trends in engineering seismology in Europe, In Proceedings of Fifth European Conference on Earthquake Engineering, Cilt. 3, s. 39-52.

[4] Blume, A. 1977. The SAM procedure for siteacceleration-magnitude relationships, In Proceedings of Sixth World Conference on Earthquake Engineering, Cilt. 1, s. 416-422.

[5] Cornell, C.A., Banon, H., Shakal, A.F. 1979. Seismic motion and response prediction alternatives, Earthquake Engineering and Structural Dynamics, Cilt. 7(4), s. 295-315.

[6] Gaull, B.A. 1988. Attenuation of strong ground motion in space and time in southwest western Australia, In Proceedings of Ninth World Conference on Earthquake Engineering, Cilt. 2, s. 361-366.

[7] Marin, S., Avouac, J.P., Nicolas, M., Schlupp, A. 2004. A probabilistic approach to seismic hazard in metropolitan France, Bulletin of the Seismological Society of America, Cilt. 94(6), s. 2137-2163.

[8] Zuccolo, E., Bozzoni, F., Lai, C.G. 2017. Regional lowmagnitude GMPE to estimate spectral accelerations for earthquake early warning applications in southern Italy, Seismological Research Letters, Cilt 88(1), s. 61-71.

[9] Idriss, I.M. 1978. Characteristics of earthquake ground motions, In Proceedings of the ASCE Geotechnical Engineering Division Speciality Conference: Earthquake Engineering and Soil Dynamics, Cilt. 3, s. 1151-1265.

[10] Algermissen, T., Hansen, S.L., Thenhaus, P.C. 1988 Seismic hazard evaluation for El Salvador. Report for the US Agency for International Development, Technical report no: 2-17, 21

[11] Castillo, W.T., Lopez, P.S., Dahle, A., Bungum, H. 1992. Digitization of strong motion data and estimation of PGA attenuation. Technical report no: 2-4, NORSAR, Kjeller, Norway, Reduction of Natural Disasters in central America Earthquake Preparedness and Hazard Mitigation Seismic Zonation and Earthquake Hazard Assessment.

[12] Wang, B.Q., Wu, F.T., Bian, Y.J. 1999. Attenuation characteristics of peak acceleration in north China and comparison with those in the eastern part of North America, Acta Seismologica Sinica, Cilt. 12(1), s. 26-34.

[13] Aydan, Ö. 2001. İstanbul Boğazı denizaltı geçişi için tüp tünel ile kalkan tünelin uygunluğunun karşılaștırılması, Jeoloji Mühendisliği Dergisi, Cilt. 25(1), s. 1-17.

[14] Sanchez, A.R., Jara, J.M. 2003. Estimación del peligro sísmico de Morelia, Ciencia Nicolaita, Cilt. 29, s. 6376.

[15] Shi, S., Shen, J. 2003. A study on attenuation relations of strong earth movements in Shanghai and its adjacent area, Earthquake Research in China, Chinese, Cilt. 19, s. 315-323.

[16] Cui, J.W., Zhang, J.G., Gao, D., Duan, J.X., Wang, T. 2012. The ground motion attenuation relation for the mountainous area in Sichuan and Yunnan. In Proceedings of Fifteenth World Conference on Earthquake Engineering, 149, Lisbon, Portugal.

[17] Youngs, R., Day, S.M., Stevens, J.L. 1988. Near-eld ground motions on rock for large subduction earthquakes. In Proceedings of Earthquake Engineering \& Soil Dynamics II, Geotechnical Division, ASCE, 445-462, Park City, Utah.

[18] Lungu, D., Demetriu, S., Radu, C., Coman, O. 1994. Uniform hazard response spectra for Vrancea earthquakes in Romania. In Proceedings of Tenth European Conference on Earthquake Engineering, 1, 365-370, Vienna, Austria

[19] Iglesias, A., Singh, S.K., Pacheco, J.F., Ordaz, M. 2002. A source and wave propagation study of the Copalillo, Mexico, earthquake of 21 July 2000 $\left(M_{w}=5.9\right)$ : Implications for seismic hazard in Mexico City from inslab earthquakes, Bulletin of the Seismological Society of America, Cilt. 92(3), s. 10601071.

[20] Popescu, E., Cioan, C.O., Radulian, M., Placinta, A.O., Moldovan, I. A. 2007. Attenuation relations for the seismic ground motion induced by Vrancea intermediate-depth earthquakes. In International Symposium on Strong Vrancea Earthquakes and Risk Mitigation, 4-6 October 2007, Bucharest, Romania.

[21] García-Soto, A.D., Jaimes, M.A. 2017. Ground-motion prediction model for vertical response spectra from Mexican interplate earthquakes, Bulletin of the Seismological Society of America, Cilt. 107(2), s. 887900.

[22] Konovalov, A.V., Manaychev, K.A., Stepnov, A.A., Gavrilov, A.V. 2019. Regional ground motion prediction equation for Sakhalin island, Seismic Instruments, Cilt. 55(1), s. 70-77.

[23] Kumar, P., Chamoli, B.P., Kumar, A., Gairola, A. 2019. Attenuation relationship for peak horizontal acceleration of strong ground motion of Uttarakhand region of central Himalayas, Journal of Earthquake Engineering, Cilt. 23, 1634161.

[24] Dahle, A., Climent, A., Taylor, W., Bungum, H., Santos, P., Ciudad Real, M., Linholm, C., Strauch, W., Segura, F. 1995. New spectral strong motion attenuation models for Central America, In Proceedings of the Fifth International Conference on Seismic Zonation, Cilt. 2, s. 1005-1012.

[25] Iervolino, I., Giorgio, M., Galasso, C., Manfredi, G. 2010. Conditional hazard maps for secondary intensity measures, Bulletin of the Seismological Society of America, Cilt. 100(6), s. 3312-3319.

[26] Kanai, K. 1966. Improved empirical formula for characteristics of stray [sic] earthquake motions. In Proceedings of the Japan Earthquake Engineering Symposium, 1-4, Tokyo-Japan.

[27] Ambraseys, N., Simpson, K.A., Bommer, J.J. 1996. Prediction of horizontal response spectra in Europe, Earthquake Engineering and Structural Dynamics, Cilt. 25(4), s. 371-400.

[28] Field, E.H. 2000. A modified ground-motion attenuation relationship for southern California that accounts for detailed site classification and a basin- 
depth effect, Bulletin of the Seismological Society of America, Cilt. 90(6B), s. S209-S221.

[29] Gençoğlu A, Sayıl N. 2019. Kuzey Anadolu Fay Zonu'nun (KAFZ) Orta Kesim İçin Yeni Bir Kuvvetli Yer Hareketi Azalım İlișkisi, Turkish Journal of Earthquake Research, Cilt. 1(1), s. 1-14.

[30] Boore, D.M., Joyner, W.B., Fumal, T.E. 1994. Estimation of response spectra and peak accelerations from western North American earthquakes: An interim report. Geological Survey, Part 2, Open-File Report 94-127.

[31] Chapman, M.C. 1999. On the use of elastic input energy for seismic hazard analysis, Earthquake Spectra, Cilt. 15(4), s. 607-635.

[32] Zare, M., Ghafory-Ashtiany, M., Bard, P.Y. 1999. Attenuation law for the strong-motions in Iran, In Proceedings of the Third International Conference on Seismology and Earthquake Engineering, Cilt. 1, s. 345-354.

[33] Ambraseys, N., Douglas, J. 2003. Near field horizontal and vertical earthquake ground motions, Soil Dynamics and Earthquake Engineering, Cilt. 23(1), s. 1-18.

[34] Cauzzi, C., Faccioli, E. 2008. Broadband (0.05 to 20 s) prediction of displacement response spectra based on worldwide digital records, Journal of Seismology, Cilt. 12(4), s. 453-475, 2008.

[35] Shoushtari, A.V., Adnan, A.Z., Zare, M. 2018. Ground motion prediction equations for distant subduction interface earthquakes based on empirical data in the Malay Peninsula and Japan, Soil Dynamics and Earthquake Engineering, Cilt. 109, s. 339-353.

[36] Wen, R., Xu, P., Wang, H., Ren, Y. 2018. Single-station standard deviation using strong-motion data from Sichuan region, China, Bulletin of the Seismological Society of America, Cilt. 108(4), s. 2237-2247.

[37] Seed, R.B., Dickenson, S.E., Reimer, M.F., Bray, J.D., Sitar, N., Mitchell, J.K., Idriss, I.M., Kayen, R.E., Kropp, A., Harder, L.F., Power, M.S. 1990. Preliminary report on the principal geotechnical aspect of the october 17, 1989 Loma prieta earthquake, Report UCB/EERC 90/05, Earthquake Engineering research Center, University of California, Berkeley, 137.

[38] Ansal, A.M. 1994. Effect of geotechnical factors and behavior of soil layers during earthquakes. State of the-Art Lecture, 10th European Conference on Earthquake Engineering, Balkema Publishers, 151157, 28 August-2 September 1994, Vienna Austria.

[39] Ansal, A.M., Lav, A.M. 1995. Geotechnical factors in 1992 Erzincan earthquake, 5 th Conference on Seismic Zonation, Nice, Cilt. 1, s. 667-674.

[40] Ansal, A.M., Siyahi, B.G. 1995. Effects of coupling between source and site characteristics during earthquakes, European Seismic Design Practice, s. 83-89.

[41] Uyanık, O., Türker, E., İsmailov, T. 2006. Sığ sismik mikro-bölgeleme ve Burdur/Türkiye örneği, Ekologiya ve $\mathrm{Su}$ Teserrüfat,, Elmi-Texniki ve istehsalat Jurnalı, Su Teserrüfatı ve Mühendis Kommunikasiya Sistemleri Fakultesi, Azerbaycan, Cilt. 1, s. 9-15.

[42] Uyanık, 0. 2015. Deprem Ağır Hasar Alanlarının Önceden Belirlenmesi ve Sehir Planlaması için Makro ve Mikro Bölgelendirmelerin Önemi,
Süleyman Demirel Üniversitesi Fen Bilimleri Enstitüsü Dergisi, Cilt. 19(2), s. 24-38.

[43] Beliceli, A. 2006. Eskişehir Yerleşim Yeri Zeminin Büyütme Etkisinin Makaslama Dalga Hızına Bağlı Olarak Belirlenmesi. Balıkesir Üniversitesi, Fen Bilimleri Enstitüsü, Yüksek Lisans Tezi, 132s, Balıkesir.

[44] Kramer, S.L. 1996, Geotechnical Earthquake Engineering, Prentice Hall, Upper Saddle River, New Jersey, USA, ISBN 0-13-374943-6.

[45] Arıoğlu, E., Arıoğlu, B., Girgin, C. 2001. Doğu Marmara Depreminin Yer İvmesi Değerleri Açısından Değerlendirilmesi, Beton Prefabrikasyon Dergisi, Cilt. 57-58, s. 5-15.

[46] Bowles, J.E. 1997. Foundation Analysis and Design, 5th edition, McGraw-Hill Companies, s. 1207.

[47] Keçeli, A. 1990. Sismik yöntemlerle müsaade edilebilir dinamik zemin taşıma kapasitesi ve oturmasının saptanması, Jeofizik, Cilt. 4(2), s. 83-92.

[48] Keçeli, A. 2000. Sismik yöntemle kabul edilebilir veya güvenli taşıma kapasitesi saptanması, Jeofizik, Cilt. 14(1-2), s. 61-72.

[49] Stokoe, K.H., Darendeli, M.B., Andrus, R.D., Brown, L.T. 1999. Dynamic soil properties: laboratory, field and correlation studies, Proceeding of the 2 nd International Conference on Earthquake Geotechnical Engineering, Cilt. 3, s. 811- 845.

[50] Uyanık, 0. 2010. Compressional and shear-wave velocity measurements in unconsolidated the topsoil and comparison of the results, International Journal of the Physical Sciences, Cilt. 5(7), s. 10341039.

[51] Uyanık, 0. 2011. The porosity of saturated shallow sediments from seismic compressional and shear wave velocities, Journal of Applied Geophysics, Cilt. 73(1), s. 16-24.

[52] Uyanık, 0. 2019. Estimation of the porosity of clay soils using seismic $P$ and $S$ wave velocities, Journal of Applied Geophysics, Cilt. 170, 103832.

[53] Andrus, R.D., Stokoe, K.H. 2000. Liquefaction resistance of soils from shear-wave velocity, Journal of Geotechnical and Geoenvironmental Engineering ASCE, Cilt. 126(11), s. 1015-1025.

[54] Uyanık, 0. 2002. Kayma dalga hızına bağlı potansiyel sıvilaşma analiz yöntemi. Dokuz Eylül Üniversitesi, Fen Bilimleri Enstitüsü, Doktora Tezi, 190s, İzmir.

[55] Uyanık, 0. 2006. Sıvılaşır yada sıvılaşmaz zeminlerin yinelemeli gerilme oranına bir seçenek, Dokuz Eylül Üniversitesi Mühendislik Fakültesi Fen ve Mühendislik Dergisi, Cilt. 8(2), s. 79-91.

[56] Uyanık, O. 2020. Soil liquefaction analysis based on soil and earthquake parameters, Journal of Applied Geophysics, Cilt. 176, 104004.

[57] Uyanık, O., Taktak, A.G. 2009. Kayma dalga hızı ve etkin titreșim periyodundan sıvılașma çözümlemesi için yeni bir yöntem, Süleyman Demirel Üniversitesi Fen Bilimleri Enstitüsü Dergisi, Cilt. 13(1), s. 74-81.

[58] Uyanık, O., Ekinci, B., Uyanık, N.A. 2013. Liquefaction analysis from seismic velocities and determination of lagoon limits Kumluca/Antalya example, Journal of Applied Geophysics, Cilt. 95, s. 90-103.

[59] Çoşkun, O. 2020. Deprem Ve Zemin Parametrelerinden En Büyük Yatay Yer İvmesinin Belirlenmesi. Süleyman Demirel Üniversitesi Fen Bilimleri Enstitüsü, Yüksek Lisans Tezi, 62s, Isparta. 
[60] Heaton, T.H., Tajima, F., Mori, A.W. 1986. Estimating ground motions using recorded accelerograms, Survey in Geophysics, Cilt. 8, s. 25-83.

[61] Xia, J., Miller, R.D., Park, C.B. 1999. Estimation of nearsurface shear-wave velocity by inversion of Rayleigh waves, Geophysics, Cilt. 64 (3), s. 691-700.

[62] Ates, E., Uyanık, 0. 2019. Jeofizik yöntemler ile yer ve yapı etkileşimi, Süleyman Demirel Üniversitesi Fen Bilimleri Enstitüsü Dergisi, Cilt. 23, s. 46-60.

[63] Uyanık, O., Catlığlu, B. 2010. Determination of density from seismic velocities, The 19th International Geophysical Congress and Exhibition of Turkey, 23-26 November 2010, Ankara, Turkey.

[64] Uyanık, O., Çatlığlu, B. 2015. Determination of density from seismic velocities. Jeofizik, Cilt. 17, s. 315.

[65] Yeşil, Y. 2012. Zemin Büyütmesinin Sismik Hızlardan Belirlenmesi. Süleyman Demirel Üniversitesi, Fen Bilimleri Enstitüsü, Yüksek Lisans Tezi, 66s, Isparta.

[66] Seed, H.B., Idriss, I.M., Kiefer, F.W. 1969. Characteristics of rock motion during earthquakes. Journal of the Soil Mechanics and Foundations Division, ASCE, Cilt. 95 (SM5), s. 1199-1218.

[67] IBM Corp. Released, 2011. IBM SPSS Statistics for Windows. Version 20.0. Armonk, NY: IBM Corp.

[68] Ulutas, E., Ozer, M.F. 2010. Empirical attenuation relationship of peak ground acceleration for Eastern Marmara region in Turkey, Arabian Journal of Science and Engineering, Cilt. 35, s. 187-203.

[69] Baag, C.E., Chang, S.J., Jo, N.D., Shin, J.S. 1998. Evaluation of seismic hazard in the southern part of Korea, In Proceedings of the Second International Symposium on Seismic Hazards and Ground Motion in the Region of Moderate Seismicity, s. 31-50.
[70] Esteva, L. 1970. Seismic risk and seismic design. In R.J. Hansen, editor, Seismic Design for Nuclear Power Plants, The M.I.T. Press, 142-182.

[71] Esteva, L., Villaverde, R. 1973. Seismic risk, design spectra and structural reliability, In Proceedings of Fifth World Conference on Earthquake Engineering, Cilt. 2, s. 2586-2596.

[72] Joyner, W.B., Boore, D.M. 1988. Measurement, characterization and prediction of strong ground motion: Earthquake Engineering and Soil Dynamics, Recent Advences in Ground Motion Evaluation, Cilt. 2, s. 43-102.

[73] Inan, E., Colakoglu, Z., Koc, N., Bayülke, N., Coruh, E. 1996. Earthquake catalogs with acceleration records from 1976 to 1996. Technical report, 98s, General Directorate of Disaster Aairs, Earthquake Research Department, Ankara, Turkey.

[74] Ansal, A.M. 1997. İstanbul için tasarım deprem özelliklerinin belirlenmesi, In Proceedings of Prof. Dr. Rifat Yarar Symposium, Cilt. 1, s. 233-244.

[75] Beyaz, T. 2004. Zemin Etkisinden Arındırılmış Deprem Kayıtlarına göre Türkiye için Yeni Bir Deprem Enerjisi Azalım Bağıntısının Geliştirilmesi. Ankara Üniversitesi, Fen Bilimleri Enstitüsü, Doktora Tezi, 271s, Ankara.

\section{Web-Kaynaklar}

$\{[1]\}$ http://kyhdata.deprem.gov.tr/2K/kyhdata_v4.php

$\{[2]\}$ https://www.orfeus-eu.org/data/strong/

$\{[3]\}$ https://wiki.anss-sis.scsn.org/SIStrac

$\{[4]\}$ https://earthquake.usgs.gov/data/vs30/

Ek-1. İvme azalım ilişkisi için kullanılan parametreler

\begin{tabular}{|c|c|c|c|c|c|c|c|c|c|c|}
\hline \multirow[b]{2}{*}{$\begin{array}{l}\text { Ölçü } \\
\text { Nok. }\end{array}$} & \multicolumn{5}{|c|}{ Deprem Parametreleri } & \multicolumn{5}{|c|}{ Zeminin Dinamik Parametreleri } \\
\hline & $\begin{array}{c}\text { Derinlik } \\
(\mathbf{k m})\end{array}$ & $\mathbf{M}_{\mathbf{w}}$ & $\begin{array}{l}R_{\text {hypo }} \\
(\mathbf{k m})\end{array}$ & $\begin{array}{l}T_{D} \\
(s)\end{array}$ & $\begin{array}{c}a_{\max } \\
\left(\mathrm{cm} / \mathrm{s}^{2}\right)\end{array}$ & $\begin{array}{l}\mathrm{T}_{0} \\
(\mathrm{~s})\end{array}$ & $\begin{array}{l}\text { Büyütme } \\
\text { (b) }\end{array}$ & $\begin{array}{c}\rho_{30} \\
\left(\mathrm{gr} / \mathrm{cm}^{3}\right)\end{array}$ & $\begin{array}{c}V_{P 30} \\
(\mathrm{~m} / \mathrm{s})\end{array}$ & $\begin{array}{c}V_{\mathrm{S} 30} \\
(\mathrm{~m} / \mathrm{s})\end{array}$ \\
\hline 1 & 27 & 5.3 & 31.9 & 0.19 & 96.7 & 0.38 & 1.75 & 1.86 & 635 & 320 \\
\hline 2 & 27 & 5.3 & 36.1 & 0.19 & 26.5 & 0.58 & 2.09 & 1.67 & 252 & 207 \\
\hline 3 & 9 & 5.3 & 34.2 & 0.19 & 23.3 & 0.43 & 1.84 & 1.80 & 486 & 282 \\
\hline 4 & 9 & 5.3 & 34.2 & 0.19 & 16.4 & 0.30 & 1.59 & 1.97 & 1037 & 403 \\
\hline 5 & 9 & 5.3 & 48.8 & 0.21 & 19.7 & 0.62 & 2.15 & 1.64 & 217 & 193 \\
\hline 6 & 9 & 5.3 & 54.7 & 0.21 & 7.7 & 0.31 & 1.61 & 1.95 & 951 & 387 \\
\hline 7 & 11 & 5.3 & 58.1 & 0.22 & 10.1 & 0.31 & 1.61 & 1.95 & 951 & 387 \\
\hline 8 & 9 & 5.3 & 60.7 & 0.22 & 4.1 & 0.37 & 1.74 & 1.86 & 639 & 321 \\
\hline 9 & 9 & 5.3 & 70.6 & 0.23 & 15.3 & 0.83 & 2.61 & 1.53 & 249 & 145 \\
\hline 10 & 27 & 5.3 & 76.0 & 0.23 & 9.6 & 0.41 & 1.81 & 1.82 & 530 & 294 \\
\hline 11 & 9 & 5.3 & 72.6 & 0.24 & 7.6 & 0.53 & 2.02 & 1.70 & 300 & 225 \\
\hline 12 & 9 & 5.3 & 74.6 & 0.24 & 5.7 & 0.42 & 1.84 & 1.80 & 489 & 283 \\
\hline 13 & 11 & 5.3 & 74.8 & 0.24 & 15.1 & 0.92 & 2.75 & 1.49 & 225 & 131 \\
\hline
\end{tabular}


DEÜ FMD 23(68), 575-593, 2021

\begin{tabular}{|c|c|c|c|c|c|c|c|c|c|c|}
\hline 14 & 9 & 5.3 & 89.5 & 0.25 & 3.9 & 0.39 & 1.78 & 1.84 & 570 & 304 \\
\hline 15 & 11 & 5.4 & 17.8 & 0.20 & 121.1 & 0.52 & 1.99 & 1.72 & 321 & 232 \\
\hline 16 & 11 & 5.4 & 33.8 & 0.20 & 25.8 & 0.34 & 1.67 & 1.91 & 797 & 356 \\
\hline 17 & 11 & 5.4 & 43.4 & 0.21 & 26.3 & 0.40 & 1.79 & 1.83 & 558 & 301 \\
\hline 18 & 11 & 5.4 & 53.2 & 0.22 & 27.2 & 0.45 & 1.88 & 1.78 & 439 & 269 \\
\hline 19 & 11 & 5.4 & 79.8 & 0.25 & 10.5 & 0.32 & 1.64 & 1.93 & 870 & 371 \\
\hline 20 & 11 & 5.4 & 81.7 & 0.26 & 6.6 & 0.42 & 1.83 & 1.81 & 497 & 285 \\
\hline 21 & 8 & 5.5 & 12.8 & 0.20 & 118.3 & 0.83 & 2.61 & 1.53 & 249 & 145 \\
\hline 22 & 10 & 5.5 & 23.4 & 0.20 & 108.3 & 0.60 & 2.12 & 1.65 & 234 & 200 \\
\hline 23 & 10 & 5.5 & 39.9 & 0.20 & 72.8 & 0.54 & 2.02 & 1.70 & 298 & 224 \\
\hline 24 & 8 & 5.5 & 47.7 & 0.22 & 31.8 & 0.30 & 1.60 & 1.96 & 994 & 395 \\
\hline 25 & 10 & 5.5 & 34.1 & 0.20 & 30.8 & 0.24 & 1.46 & 2.08 & 1626 & 498 \\
\hline 26 & 11 & 5.5 & 35.7 & 0.20 & 26.4 & 0.33 & 1.65 & 1.93 & 850 & 367 \\
\hline 27 & 10 & 5.5 & 37.7 & 0.20 & 18.3 & 0.17 & 1.27 & 2.26 & 3331 & 698 \\
\hline 28 & 11 & 5.5 & 66.8 & 0.25 & 17.0 & 0.71 & 2.40 & 1.59 & 292 & 170 \\
\hline 29 & 11 & 5.5 & 51.2 & 0.22 & 15.3 & 0.34 & 1.67 & 1.91 & 797 & 356 \\
\hline 30 & 8 & 5.5 & 70.5 & 0.25 & 13.2 & 0.52 & 1.99 & 1.72 & 321 & 232 \\
\hline 31 & 8 & 5.5 & 100.3 & 0.29 & 10.3 & 0.40 & 1.79 & 1.83 & 558 & 301 \\
\hline 32 & 8 & 5.5 & 85.4 & 0.27 & 10.3 & 0.31 & 1.61 & 1.96 & 967 & 390 \\
\hline 33 & 11 & 5.5 & 93.7 & 0.28 & 7.2 & 0.61 & 2.13 & 1.65 & 229 & 198 \\
\hline 34 & 8 & 5.5 & 95.3 & 0.28 & 5.9 & 0.48 & 1.94 & 1.75 & 370 & 248 \\
\hline 35 & 8 & 5.5 & 84.4 & 0.27 & 5.7 & 0.32 & 1.64 & 1.93 & 875 & 372 \\
\hline 36 & 11 & 5.6 & 15.6 & 0.21 & 242.1 & 0.46 & 1.91 & 1.77 & 405 & 259 \\
\hline 37 & 9 & 5.6 & 20.7 & 0.21 & 229.4 & 0.26 & 1.51 & 2.03 & 1336 & 454 \\
\hline 38 & 9.1 & 5.6 & 14.8 & 0.21 & 229.0 & 0.47 & 1.92 & 1.76 & 389 & 254 \\
\hline 39 & 11 & 5.6 & 32.0 & 0.21 & 65.2 & 0.35 & 1.70 & 1.89 & 736 & 343 \\
\hline 40 & 11 & 5.6 & 42.5 & 0.22 & 58.3 & 0.36 & 1.71 & 1.88 & 705 & 336 \\
\hline 41 & 46.6 & 5.6 & 80.0 & 0.25 & 20.2 & 0.32 & 1.64 & 1.94 & 890 & 375 \\
\hline 42 & 11 & 5.6 & 96.6 & 0.30 & 19.7 & 0.40 & 1.79 & 1.83 & 558 & 301 \\
\hline 43 & 11 & 5.6 & 58.1 & 0.24 & 15.9 & 0.42 & 1.83 & 1.81 & 497 & 285 \\
\hline 44 & 7 & 5.6 & 91.3 & 0.29 & 15.2 & 0.61 & 2.14 & 1.65 & 224 & 196 \\
\hline 45 & 7 & 5.6 & 95.3 & 0.29 & 15.1 & 0.34 & 1.67 & 1.91 & 806 & 358 \\
\hline 46 & 9.1 & 5.6 & 53.9 & 0.24 & 13.6 & 0.12 & 1.04 & 2.46 & 3965 & 976 \\
\hline 47 & 46.6 & 5.6 & 80.0 & 0.25 & 10.7 & 0.23 & 1.42 & 2.11 & 1848 & 529 \\
\hline 48 & 9.1 & 5.6 & 84.6 & 0.28 & 10.6 & 0.42 & 1.84 & 1.80 & 489 & 283 \\
\hline 49 & 7 & 5.6 & 87.3 & 0.28 & 8.0 & 0.38 & 1.76 & 1.85 & 614 & 315 \\
\hline 50 & 46.6 & 5.7 & 47.7 & 0.22 & 223.4 & 0.83 & 2.61 & 1.53 & 249 & 145 \\
\hline 51 & 34 & 5.7 & 40.7 & 0.22 & 168.8 & 0.60 & 2.12 & 1.65 & 234 & 200 \\
\hline
\end{tabular}


DEÜ FMD 23(68), 575-593, 2021

\begin{tabular}{|c|c|c|c|c|c|c|c|c|c|c|}
\hline 52 & 16 & 5.7 & 80.1 & 0.28 & 44.6 & 0.47 & 1.91 & 1.76 & 402 & 258 \\
\hline 53 & 16 & 5.7 & 40.1 & 0.22 & 21.5 & 0.17 & 1.25 & 2.26 & 2824 & 698 \\
\hline 54 & 16 & 5.7 & 61.2 & 0.25 & 19.6 & 0.15 & 1.16 & 2.34 & 3246 & 800 \\
\hline 55 & 16 & 5.7 & 68.7 & 0.26 & 18.4 & 0.71 & 2.40 & 1.59 & 292 & 170 \\
\hline 56 & 16 & 5.7 & 101.3 & 0.31 & 15.0 & 0.36 & 1.71 & 1.88 & 700 & 335 \\
\hline 57 & 16 & 5.7 & 84.3 & 0.29 & 6.9 & 0.17 & 1.25 & 2.26 & 2824 & 696 \\
\hline 58 & 11.3 & 6.0 & 15.1 & 0.24 & 264.6 & 0.27 & 1.52 & 2.02 & 1280 & 445 \\
\hline 59 & 9.5 & 6.0 & 22.8 & 0.24 & 205.9 & 0.38 & 1.76 & 1.85 & 602 & 312 \\
\hline 60 & 9.5 & 6.0 & 46.6 & 0.25 & 147.1 & 0.40 & 1.80 & 1.83 & 542 & 297 \\
\hline 61 & 19.5 & 6.0 & 30.5 & 0.24 & 138.8 & 0.22 & 1.39 & 2.14 & 2047 & 555 \\
\hline 62 & 11.3 & 6.0 & 15.3 & 0.24 & 126.0 & 0.15 & 1.18 & 2.33 & 3191 & 780 \\
\hline 63 & 16 & 6.0 & 57.3 & 0.27 & 64.1 & 0.61 & 2.13 & 1.65 & 229 & 198 \\
\hline 64 & 22 & 6.0 & 32.8 & 0.24 & 62.1 & 0.17 & 1.25 & 2.26 & 2824 & 698 \\
\hline 65 & 16 & 6.0 & 60.2 & 0.27 & 60.1 & 0.41 & 1.81 & 1.82 & 530 & 294 \\
\hline 66 & 9.5 & 6.0 & 53.1 & 0.26 & 59.8 & 0.35 & 1.71 & 1.89 & 718 & 339 \\
\hline 67 & 9.5 & 6.0 & 66.3 & 0.29 & 49.0 & 0.23 & 1.42 & 2.11 & 1878 & 533 \\
\hline 68 & 9.5 & 6.0 & 78.2 & 0.31 & 49.0 & 0.22 & 1.40 & 2.13 & 1985 & 547 \\
\hline 69 & 25 & 6.0 & 61.3 & 0.27 & 33.9 & 0.71 & 2.40 & 1.59 & 292 & 170 \\
\hline 70 & 9.5 & 6.0 & 75.9 & 0.30 & 29.4 & 0.20 & 1.34 & 2.18 & 2467 & 606 \\
\hline 71 & 11.3 & 6.0 & 50.9 & 0.26 & 25.1 & 0.12 & 1.04 & 2.46 & 3965 & 976 \\
\hline 72 & 11.3 & 6.0 & 83.6 & 0.32 & 24.3 & 0.42 & 1.84 & 1.80 & 489 & 283 \\
\hline 73 & 16 & 6.0 & 60.2 & 0.27 & 19.3 & 0.52 & 1.99 & 1.72 & 321 & 232 \\
\hline 74 & 16 & 6.0 & 34.9 & 0.24 & 18.7 & 0.15 & 1.16 & 2.34 & 3246 & 805 \\
\hline 75 & 16 & 6.0 & 88.5 & 0.32 & 17.9 & 0.34 & 1.67 & 1.91 & 801 & 357 \\
\hline 76 & 16 & 6.0 & 64.0 & 0.28 & 17.5 & 0.33 & 1.65 & 1.93 & 850 & 367 \\
\hline 77 & 23 & 6.0 & 73.8 & 0.29 & 16.3 & 0.25 & 1.49 & 2.05 & 1464 & 474 \\
\hline 78 & 16 & 6.0 & 91.4 & 0.33 & 14.8 & 0.27 & 1.52 & 2.02 & 1280 & 445 \\
\hline 79 & 23 & 6.0 & 55.9 & 0.26 & 14.4 & 0.54 & 2.02 & 1.70 & 298 & 224 \\
\hline 80 & 11.3 & 6.0 & 85.8 & 0.32 & 12.2 & 0.12 & 1.09 & 2.47 & 7167 & 1001 \\
\hline 81 & 27 & 6.0 & 98.8 & 0.34 & 12.1 & 0.33 & 1.66 & 1.92 & 825 & 362 \\
\hline 82 & 23 & 6.0 & 73.7 & 0.29 & 11.4 & 0.22 & 1.40 & 2.13 & 2000 & 549 \\
\hline 83 & 16 & 6.0 & 94.4 & 0.33 & 10.7 & 0.42 & 1.83 & 1.81 & 497 & 285 \\
\hline 84 & 16 & 6.0 & 70.8 & 0.29 & 7.7 & 0.35 & 1.69 & 1.90 & 745 & 345 \\
\hline 85 & 27 & 6.0 & 68.5 & 0.28 & 6.5 & 0.23 & 1.42 & 2.11 & 1856 & 530 \\
\hline 86 & 19 & 6.0 & 72.9 & 0.30 & 4.9 & 0.14 & 1.13 & 2.37 & 3416 & 836 \\
\hline 87 & 16 & 6.0 & 100.3 & 0.34 & 4.4 & 0.17 & 1.27 & 2.26 & 3291 & 694 \\
\hline 88 & 16 & 6.0 & 90.4 & 0.33 & 4.0 & 0.35 & 1.70 & 1.89 & 741 & 344 \\
\hline 89 & 16 & 6.0 & 99.3 & 0.34 & 3.6 & 0.40 & 1.79 & 1.83 & 558 & 301 \\
\hline
\end{tabular}


DEÜ FMD 23(68), 575-593, 2021

\begin{tabular}{|c|c|c|c|c|c|c|c|c|c|c|}
\hline 90 & 19 & 6.1 & 58.2 & 0.28 & 53.4 & 0.23 & 1.43 & 2.10 & 1782 & 520 \\
\hline 91 & 19 & 6.1 & 47.9 & 0.26 & 50.1 & 0.30 & 1.60 & 1.96 & 1004 & 397 \\
\hline 92 & 10.4 & 6.1 & 74.7 & 0.31 & 34.9 & 0.25 & 1.49 & 2.05 & 1451 & 472 \\
\hline 93 & 10.4 & 6.1 & 84.6 & 0.33 & 27.4 & 0.54 & 2.03 & 1.70 & 295 & 223 \\
\hline 94 & 10.5 & 6.2 & 45.2 & 0.26 & 59.1 & 0.37 & 1.73 & 1.87 & 669 & 328 \\
\hline 95 & 10 & 6.2 & 30.7 & 0.25 & 50.1 & 0.58 & 2.09 & 1.67 & 252 & 207 \\
\hline 96 & 10 & 6.2 & 61.8 & 0.30 & 39.0 & 0.31 & 1.61 & 1.95 & 951 & 387 \\
\hline 97 & 21 & 6.2 & 64.5 & 0.30 & 38.8 & 0.23 & 1.42 & 2.11 & 1871 & 532 \\
\hline 98 & 10.5 & 6.2 & 61.9 & 0.30 & 35.5 & 0.31 & 1.61 & 1.95 & 951 & 387 \\
\hline 99 & 21 & 6.2 & 73.1 & 0.31 & 30.9 & 0.29 & 1.57 & 1.98 & 1098 & 414 \\
\hline 100 & 10 & 6.2 & 68.7 & 0.31 & 29.7 & 0.32 & 1.64 & 1.93 & 875 & 372 \\
\hline 101 & 21 & 6.2 & 82.7 & 0.33 & 29.2 & 0.38 & 1.76 & 1.85 & 606 & 313 \\
\hline 102 & 10.4 & 6.2 & 80.7 & 0.33 & 27.1 & 0.30 & 1.60 & 1.96 & 994 & 395 \\
\hline 103 & 10 & 6.2 & 95.5 & 0.36 & 25.9 & 0.22 & 1.39 & 2.14 & 2070 & 558 \\
\hline 104 & 10 & 6.2 & 90.6 & 0.35 & 25.5 & 0.48 & 1.94 & 1.75 & 373 & 249 \\
\hline 105 & 21 & 6.2 & 76.0 & 0.32 & 25.0 & 0.26 & 1.50 & 2.04 & 1373 & 460 \\
\hline 106 & 21 & 6.2 & 81.7 & 0.33 & 25.0 & 0.26 & 1.51 & 2.04 & 1367 & 459 \\
\hline 107 & 10 & 6.2 & 86.6 & 0.34 & 24.9 & 0.61 & 2.14 & 1.65 & 224 & 196 \\
\hline 108 & 21 & 6.2 & 82.7 & 0.33 & 20.3 & 0.70 & 2.39 & 1.59 & 294 & 171 \\
\hline 109 & 10 & 6.2 & 91.6 & 0.35 & 20.2 & 0.44 & 1.87 & 1.78 & 443 & 270 \\
\hline 110 & 10.5 & 6.2 & 78.7 & 0.33 & 19.2 & 0.31 & 1.60 & 1.96 & 983 & 393 \\
\hline 111 & 10 & 6.2 & 97.5 & 0.36 & 18.6 & 0.35 & 1.70 & 1.89 & 722 & 340 \\
\hline 112 & 10 & 6.2 & 86.6 & 0.34 & 18.4 & 0.40 & 1.80 & 1.83 & 546 & 298 \\
\hline 113 & 10 & 6.2 & 87.6 & 0.34 & 17.7 & 0.16 & 1.23 & 2.30 & 3826 & 745 \\
\hline 114 & 10 & 6.2 & 90.6 & 0.35 & 17.2 & 0.48 & 1.94 & 1.75 & 373 & 249 \\
\hline 115 & 10 & 6.2 & 88.6 & 0.35 & 14.4 & 0.26 & 1.49 & 2.05 & 1425 & 468 \\
\hline 116 & 10 & 6.2 & 84.6 & 0.34 & 13.5 & 0.14 & 1.13 & 2.37 & 3416 & 836 \\
\hline 117 & 10 & 6.2 & 88.6 & 0.35 & 11.1 & 0.14 & 1.11 & 2.39 & 3533 & 875 \\
\hline 118 & 10 & 6.2 & 95.5 & 0.36 & 10.4 & 0.15 & 1.14 & 2.36 & 3358 & 827 \\
\hline 119 & 10 & 6.3 & 15.6 & 0.26 & 545.5 & 0.23 & 1.42 & 2.11 & 1848 & 529 \\
\hline 120 & 10 & 6.3 & 87.6 & 0.35 & 21.3 & 0.63 & 2.16 & 1.64 & 215 & 192 \\
\hline 121 & 10 & 6.3 & 87.6 & 0.35 & 10.3 & 0.34 & 1.68 & 1.90 & 768 & 350 \\
\hline 122 & 10 & 6.3 & 102.5 & 0.38 & 19.4 & 0.31 & 1.61 & 1.95 & 951 & 387 \\
\hline 123 & 19 & 6.7 & 26.2 & 0.29 & 621.7 & 0.30 & 1.60 & 1.97 & 1010 & 398 \\
\hline 124 & 19 & 6.7 & 27.4 & 0.29 & 598.2 & 0.45 & 1.88 & 1.78 & 439 & 269 \\
\hline 125 & 19 & 6.7 & 29.8 & 0.29 & 393.3 & 0.38 & 1.76 & 1.86 & 618 & 316 \\
\hline 126 & 19 & 6.7 & 38.1 & 0.29 & 291.3 & 0.35 & 1.70 & 1.89 & 732 & 342 \\
\hline 127 & 15 & 6.9 & 24.1 & 0.30 & 171.5 & 0.22 & 1.39 & 2.14 & 2062 & 557 \\
\hline
\end{tabular}


DEÜ FMD 23(68), 575-593, 2021

\begin{tabular}{|l|c|c|c|c|c|c|c|c|c|c|}
\hline $\mathbf{1 2 8}$ & $\mathbf{1 5}$ & 6.9 & 26.5 & 0.30 & 183.6 & 0.24 & 1.46 & 2.08 & 1626 & 498 \\
\hline $\mathbf{1 2 9}$ & $\mathbf{1 5}$ & 6.9 & 27.8 & 0.30 & 56.3 & 0.12 & 1.02 & 2.49 & 4162 & 1018 \\
\hline $\mathbf{1 3 0}$ & $\mathbf{1 5}$ & 6.9 & 32.0 & 0.30 & 94.5 & 0.12 & 1.05 & 2.46 & 3965 & 972 \\
\hline $\mathbf{1 3 1}$ & $\mathbf{1 5}$ & 6.9 & 38.5 & 0.30 & 97.3 & 0.22 & 1.41 & 2.12 & 1923 & 539 \\
\hline $\mathbf{1 3 2}$ & $\mathbf{1 5}$ & 6.9 & 49.4 & 0.32 & 138.2 & 0.27 & 1.51 & 2.03 & 1323 & 452 \\
\hline $\mathbf{1 3 3}$ & $\mathbf{1 5}$ & 6.9 & 56.4 & 0.34 & 47.0 & 0.34 & 1.67 & 1.91 & 797 & 356 \\
\hline $\mathbf{1 3 4}$ & $\mathbf{1 5}$ & 6.9 & 60.6 & 0.35 & 43.5 & 0.16 & 1.23 & 2.30 & 3815 & 744 \\
\hline $\mathbf{1 3 5}$ & $\mathbf{1 5}$ & 6.9 & 74.7 & 0.38 & 45.5 & 0.27 & 1.52 & 2.02 & 1286 & 446 \\
\hline $\mathbf{1 3 6}$ & $\mathbf{1 5}$ & 6.9 & 78.3 & 0.39 & 33.9 & 0.21 & 1.37 & 2.16 & 2223 & 577 \\
\hline $\mathbf{1 3 7}$ & $\mathbf{1 5}$ & 6.9 & 79.8 & 0.39 & 58.7 & 0.28 & 1.54 & 2.01 & 1220 & 435 \\
\hline $\mathbf{1 3 8}$ & $\mathbf{1 8}$ & 7.0 & 20.6 & 0.31 & 627.6 & 0.26 & 1.50 & 2.04 & 1386 & 462 \\
\hline $\mathbf{1 3 9}$ & $\mathbf{1 8}$ & 7.0 & 20.6 & 0.31 & 588.4 & 0.42 & 1.82 & 1.81 & 511 & 289 \\
\hline $\mathbf{1 4 0}$ & $\mathbf{1 8}$ & 7.0 & 27.4 & 0.31 & 441.3 & 0.11 & 1.00 & 2.52 & 4366 & 1070 \\
\hline $\mathbf{1 4 1}$ & $\mathbf{1 8}$ & 7.0 & 33.0 & 0.31 & 519.8 & 0.31 & 1.63 & 1.94 & 920 & 381 \\
\hline $\mathbf{1 4 2}$ & $\mathbf{1 8}$ & 7.0 & 34.0 & 0.31 & 362.9 & 0.16 & 1.24 & 2.29 & 3664 & 730 \\
\hline $\mathbf{1 4 3}$ & $\mathbf{1 8}$ & 7.0 & 34.7 & 0.31 & 362.9 & 0.44 & 1.87 & 1.79 & 446 & 271 \\
\hline $\mathbf{1 4 4}$ & $\mathbf{1 8}$ & 7.0 & 36.1 & 0.31 & 539.4 & 0.43 & 1.85 & 1.80 & 471 & 278 \\
\hline $\mathbf{1 4 5}$ & $\mathbf{1 8}$ & 7.0 & 43.8 & 0.31 & 323.6 & 0.36 & 1.72 & 1.88 & 696 & 334 \\
\hline $\mathbf{1 4 6}$ & $\mathbf{1 8}$ & 7.0 & 81.5 & 0.41 & 323.6 & 0.63 & 2.17 & 1.63 & 210 & 190 \\
\hline $\mathbf{1 4 7}$ & $\mathbf{1 8}$ & 7.0 & 99.7 & 0.45 & 205.9 & 0.20 & 1.35 & 2.17 & 2364 & 594 \\
\hline $\mathbf{1 4 8}$ & $\mathbf{1 0 . 4}$ & 7.1 & 37.5 & 0.31 & 805.9 & 0.41 & 1.81 & 1.82 & 530 & 294 \\
\hline $\mathbf{1 4 9}$ & $\mathbf{1 0 . 4}$ & 7.1 & 39.4 & 0.31 & 121.0 & 0.34 & 1.67 & 1.91 & 792 & 355 \\
\hline $\mathbf{1 5 0}$ & $\mathbf{1 0 . 4}$ & 7.1 & 57.9 & 0.36 & 27.9 & 0.34 & 1.69 & 1.90 & 759 & 348 \\
\hline $\mathbf{1 5 1}$ & $\mathbf{1 0 . 4}$ & 7.1 & 68.8 & 0.39 & 24.7 & 0.29 & 1.57 & 1.98 & 1087 & 412 \\
\hline $\mathbf{1 5 2}$ & $\mathbf{1 0 . 4}$ & 7.1 & 107.5 & 0.49 & 23.9 & 0.15 & 1.14 & 2.36 & 3358 & 826 \\
\hline
\end{tabular}

